OPEN ACCESS

Edited by:

Joanne O'Callaghan,

National Institute of Water and Atmospheric Research (NIWA),

New Zealand

Reviewed by:

Zhaoqing Yang,

Pacific Northwest National Laboratory

(DOE), United States

Klaus Wallmann,

GEOMAR Helmholtz Center for Ocean

Research Kiel, Germany

${ }^{*}$ Correspondence: Clare Bradshaw clare.bradshaw@su.se

Specialty section:

This article was submitted to Coastal Ocean Processes,

a section of the journal

Frontiers in Marine Science

Received: 20 March 2021

Accepted: 22 July 2021

Published: 25 August 2021

Citation:

Bradshaw C, Jakobsson $M$, Brüchert V, Bonaglia S, Mörth C-M, Muchowski J, Stranne $C$ and Sköld M

(2021) Physical Disturbance by

Bottom Trawling Suspends Particulate Matter and Alters Biogeochemical Processes on and Near the Seafloor.

Front. Mar. Sci. 8:683331.

doi: 10.3389/fmars.2021.683331

\section{Physical Disturbance by Bottom Trawling Suspends Particulate Matter and Alters Biogeochemical Processes on and Near the Seafloor}

\author{
Clare Bradshaw ${ }^{1 *}$, Martin Jakobsson², Volker Brüchert², Stefano Bonaglia', \\ Carl-Magnus Mörth², Julia Muchowski², Christian Stranne ${ }^{2}$ and Mattias Sköld ${ }^{3}$ \\ ${ }^{1}$ Department of Ecology, Environment and Plant Sciences, Stockholm University, Stockholm, Sweden, ${ }^{2}$ Department \\ of Geological Sciences, Stockholm University, Stockholm, Sweden, ${ }^{3}$ Department of Aquatic Resources, Institute of Marine \\ Research, Swedish University of Agricultural Sciences, Lysekil, Sweden
}

Bottom trawling is known to affect benthic faunal communities but its effects on sediment suspension and seabed biogeochemistry are less well described. In addition, few studies have been carried out in the Baltic Sea, despite decades of trawling in this unique brackish environment and the frequent occurrence of trawling in areas where hypoxia and low and variable salinity already act as ecosystem stressors. We measured the physical and biogeochemical impacts of an otter trawl on a muddy Baltic seabed. Multibeam bathymetry revealed a 36 m-wide trawl track, comprising parallel furrows and sediment piles caused by the trawl doors and shallower grooves from the groundgear, that displaced 1,000 $\mathrm{m}^{3}$ (500 t) sediment and suspended $9.5 \mathrm{t}$ sediment per $\mathrm{km}$ of track. The trawl doors had less effect than the rest of the gear in terms of total sediment mass but per $\mathrm{m}^{2}$ the doors had $5 \times$ the displacement and $2 x$ the suspension effect, due to their greater penetration and hydrodynamic drag. The suspended sediment spread $>1 \mathrm{~km}$ away over the following 3-4 days, creating a 5-10 m thick layer of turbid bottom water. Turbidity reached 4.3 NTU (7 mgDW $\mathrm{L}^{-1}$ ), $550 \mathrm{~m}$ from the track, $20 \mathrm{~h}$ post-trawling. Particulate $\mathrm{Al}, \mathrm{Ti}, \mathrm{Fe}, \mathrm{P}$, and $\mathrm{Mn}$ were correlated with the spatio-temporal pattern of suspension. There was a pulse of dissolved $\mathrm{N}, \mathrm{P}$, and $\mathrm{Mn}$ to a height of $10 \mathrm{~m}$ above the seabed within a few hundred meters of the track, $2 \mathrm{~h}$ post-trawling. Dissolved methane concentrations were elevated in the water for at least $20 \mathrm{~h}$. Sediment biogeochemistry in the door track was still perturbed after $48 \mathrm{~h}$, with a decreased oxygen penetration depth and nutrient and oxygen fluxes across the sediment-water interface. These results clearly show the physical effects of bottom trawling, both on seabed topography (on the scale of $\mathrm{km}$ and years) and on sediment and particle suspension (on the scale of km and daysweeks). Alterations to biogeochemical processes suggest that, where bottom trawling is frequent, sediment biogeochemistry may not have time to recover between disturbance events and elevated turbidity may persist, even outside the trawled area.

Keywords: otter trawl, sediment suspension, turbidity, biogeochemistry, disturbance, nutrients, oxygen, multibeam echo-sounding 


\section{INTRODUCTION}

Bottom trawling is used worldwide as a method of catching benthic or demersal fish and shellfish and even several decades ago was estimated to impact an area equivalent to $75 \%$ of the world's continental shelf (Kaiser et al., 2002). In some coastal areas, trawling intensity is such that the seabed is trawled more than 10 times per year (Eigaard et al., 2017) and/or $>80 \%$ of the seabed area is trawled every year (Eigaard et al., 2017; Amoroso et al., 2018).

While effects on benthic community structure are welldescribed (Jennings and Kaiser, 1998; Kaiser et al., 2006; Hiddink et al., 2017; Rijnsdorp et al., 2018), there are fewer studies on the physical or biogeochemical impacts on the seabed, or on sediment suspension. Some parts of the fishing gear have direct contact with the seabed (Ivanović et al., 2011; Martín et al., 2014). In addition, changes in hydrodynamics and pressure fields around the towed gear also disturb sediments (O'Neill and Ivanović, 2016). Physical disturbance of the seabed can either lead to increased heterogeneity/roughness, e.g., in areas of low fishing intensity and on flat sedimentary bottoms, or decreased roughness, e.g., in areas of high fishing intensity and/or where seafloor structures are leveled (Martín et al., 2014). The parallel furrows left by trawl door tracks on soft sediments are particularly easy to detect with acoustic mapping methods, e.g., side-scan sonar and multibeam, and such tracks can remain for many years (Krost et al., 1990; Oberle et al., 2018; Bunke et al., 2019).

Disturbance suspends sediment into the water column, increasing turbidity by orders of magnitude (Black and Parry, 1994; Durrieu de Madron et al., 2005; Dounas, 2006; Dellapenna et al., 2006; Dounas et al., 2007; O’Neill and Summerbell, 2011; O’Neill et al., 2013a,b; Mengual et al., 2016) and increasing sedimentation rates downslope (Puig et al., 2015; Paradis et al., 2017, 2018), both of which may have negative effects on marine organisms (Wenger et al., 2017; Magris and Ban, 2019). More sediment is suspended in areas with a high proportion of silt and clay (Oberle et al., 2016a). Fine particles can be winnowed out and advected by currents to other areas (Ferré et al., 2008; Palanques et al., 2014; Mengual et al., 2016; Oberle et al., 2016b). In some areas, trawling may contribute significantly to near-bottom turbidity, sediment suspension, and sedimentation budgets (Churchill, 1989; Pilskaln et al., 1998; Dellapenna et al., 2006; Ferré et al., 2008; Bradshaw et al., 2012; Martín et al., 2014; Paradis et al., 2017; Oberle et al., 2018). Overall effects and their persistence depend on gear type, sediment type, and natural sediment dynamics of the area (Oberle et al., 2018).

Trawling has been shown to alter surface sediment properties; for example, either increasing particle sizes through the winnowing of smaller fractions (Watling et al., 2001; Brown et al., 2005; Palanques et al., 2014) or decreasing them by the removal or breakup of larger particles (Bradshaw et al., 2002). Organic carbon content in surface sediments may be higher (Pusceddu et al., 2005; Palanques et al., 2014) or lower (Martín et al., 2014) in trawled sediments, and the type of organic matter may also be affected (Watling et al., 2001; Pusceddu et al., 2005). The overall effect on sediment properties depends on the original sediment type but also on trawling frequency, local current regimes and whether trawling causes a net removal/erosion of surface sediments or mixing of surface and deeper layers (Martín et al., 2014; Oberle et al., 2016b, 2018).

The few existing studies of biogeochemical effects of trawling have produced contradictory results. A number of authors report no measureable effects on nutrient fluxes (Smith et al., 2000; Zacharia et al., 2006; Olsgard et al., 2008), while others have shown short term effluxes of some nutrients from sediments (Krost, 1990; Durrieu de Madron et al., 2005; Dounas, 2006; Dounas et al., 2007), confirmed by sediment suspension experiments (Krost et al., 1990; Percival et al., 2005) and models (Blackburn, 1997; Duplisea et al., 2001). Increased carbon mineralization rates have also been seen (van de Velde et al., 2018). Effects are likely dependent on the depth of the redox potential discontinuity relative to the depth of disturbance (Warnken et al., 2003), altered redox pathways (van de Velde et al., 2018), the types of organisms present in the sediment (Olsgard et al., 2008), and the timescale over which measurements are made. Dounas et al. (2007) calculated that releases of nutrients could support $15 \%$ of productivity in the oligotrophic Bay of Heraklion. However, other authors suggest that short term pulse releases of nutrients from trawling do not increase the overall long-term nutrient concentrations or availability (Sloth et al., 1996; Blackburn, 1997; Trimmer et al., 2005). Two recent studies suggest that bottom trawling could impact regional and even global carbon storage capacity of marine sediments (Legge et al., 2020; Sala et al., 2021).

The Baltic Sea is one of the largest brackish water bodies in the world and is subject to a range of anthropogenic stressors. Many species and habitats are in poor condition (HELCOM, 2018), and the most important anthropogenic pressures are identified as nutrient and organic enrichment, selective extraction of species, contaminants, non-indigenous species and abrasion and substrate loss, the latter partly caused by bottom trawling (ICES, 2020a). Bottom trawling mainly occurs in the southern Baltic Proper using otter trawls, and the target species are cod (Gadus morhua) and the European flounder (Platichthys flesus) (ICES, 2018). Although fishing intensity has been relatively low during the last few years due to the poor status of Baltic cod stocks, fishing intensity was high from the 1970s to early 2000s (ICES, 2018, 2020b,c). However, very few studies in the Baltic Sea have attempted to evaluate bottom trawling impacts. An early study in the Kiel Bight (Krost, 1990; Krost et al., 1990) described how otter trawling caused physical disturbance of the seafloor, changes to benthic communities and, using experiments and calculations, hypothesized that dissolved nutrients might be released when these sediments were suspended. More recently, van Denderen et al. (2020) estimated that a combination of trawling disturbance and hypoxia reduced the benthic community biomass by at least $50 \%$ in $14 \%$ of the Baltic Sea. Bunke et al. (2019) saw evidence of extensive disruption of sedimentary fabrics by trawling in the south-west Baltic Sea, although bioturbation, storms and marine water inflows also contributed to the disruption. Given that many areas of the Baltic Proper comprise soft sediment seabeds, physical disturbance by trawling can be expected to cause sediment suspension and affect biogeochemical processes across the sediment-water interface; however, data is lacking. 
Given the lack of data on trawling impacts in the Baltic Sea and the generally poor understanding of how trawling impacts sediment suspension and biogeochemical processes, we performed a controlled field experiment using a commercial otter trawl to quantify the physical and biogeochemical impacts of bottom trawling on a Baltic Sea seabed. Using acoustic mapping and water and sediment sampling, we quantified the extent of physical seabed disturbance, suspension of particulate matter, and the release and fluxes of dissolved substances from the sediment over 4 days and up to c. $1.5 \mathrm{~km}$ from the trawl track.

\section{MATERIALS AND METHODS}

\section{Description of the Study Area and Overview of the Field Experiment}

The study area is located in the north-west Baltic Proper (Figure 1). The area is quite sheltered from all wind directions by the mainland and numerous surrounding islands. The seabed where the trawling was carried out comprises unconsolidated gyttja clay sediments at 20-35 m depth (Jakobsson et al., 2020; Supplementary Figure 2). The area is non-tidal and water currents are generally slow.

A small $(12 \mathrm{~m} \times 4 \mathrm{~m})$ commercial trawler with an otter trawl was used (Figure 2) to create a single trawl track. The two metal trawl doors, $110 \mathrm{~cm}$ high and $160 \mathrm{~cm}$ long, weighing $\mathrm{c}$. $230 \mathrm{~kg}$ each, were connected by $50 \mathrm{~m}$ sweeps to the headline and groundgear which comprised a row of rubber discs. The net was $65 \mathrm{~m}$ long and kept open vertically by six groups of three floats attached approximately half way between the headline and the codend.

The bathymetry of the area was acoustically mapped with a multibeam echo sounder (EM2040, see below) in May 2018. Immediately prior to the experimental trawling (22 October 2018), and along the planned trawl track, two CTD (Conductivity, Temperature, Depth) and water sample profiles

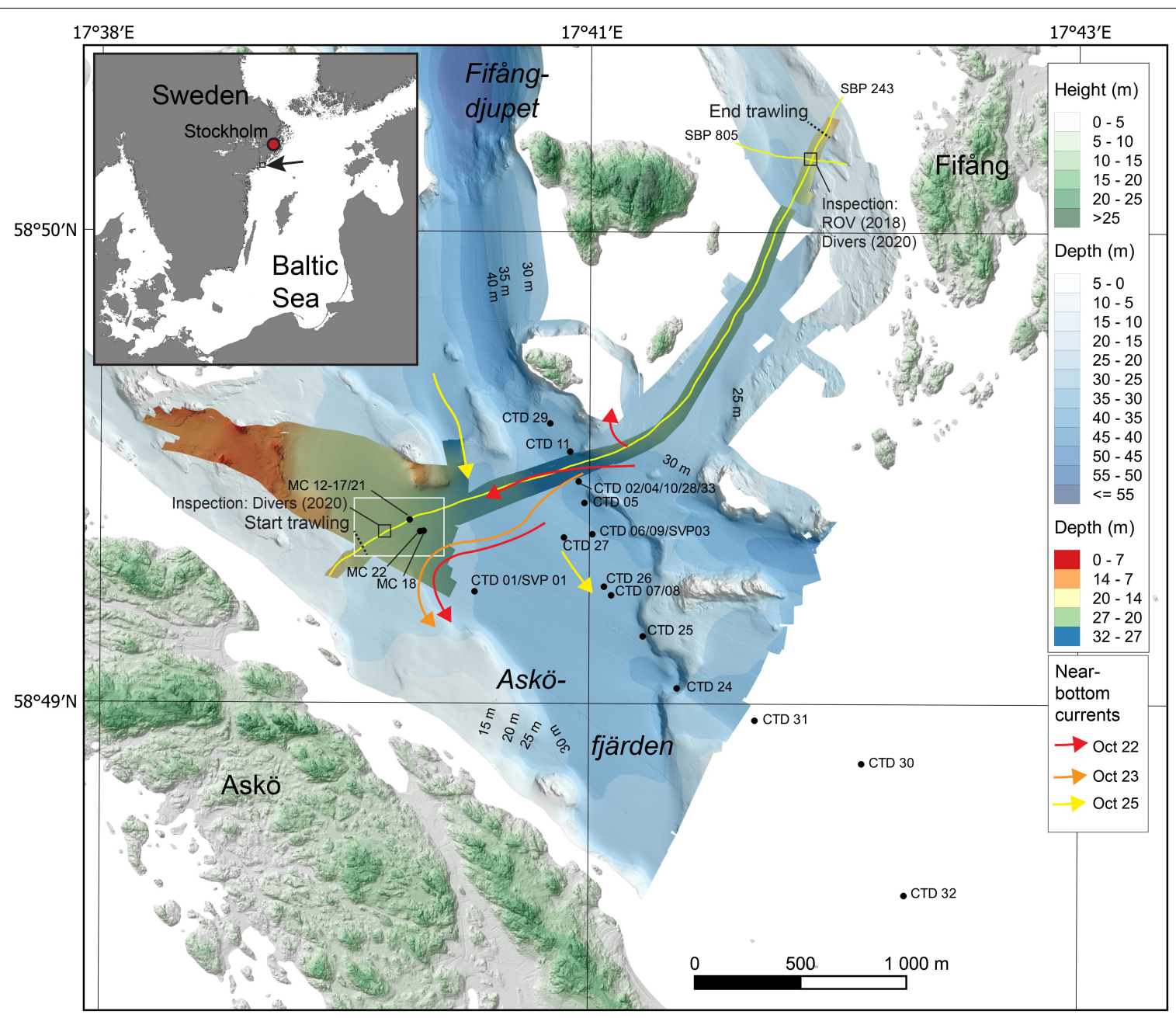

FIGURE 1 | Overview map of sampling sites, multibeam bathymetry acquired for this study (rainbow colored depth scale) and sub-bottom profile acquired 4 days after trawling (yellow line). Generalized current directions for the deeper water (0-15 m.a.b.) are indicated with arrows color-coded for day (see legend). The white box outlines the area of the trawl tracks shown in Figure $\mathbf{3 b}$. CTD, Conductivity Temperature Depth; MC, Multicore; SBP, sub-bottom profiling; SVP, sound velocity profile. 

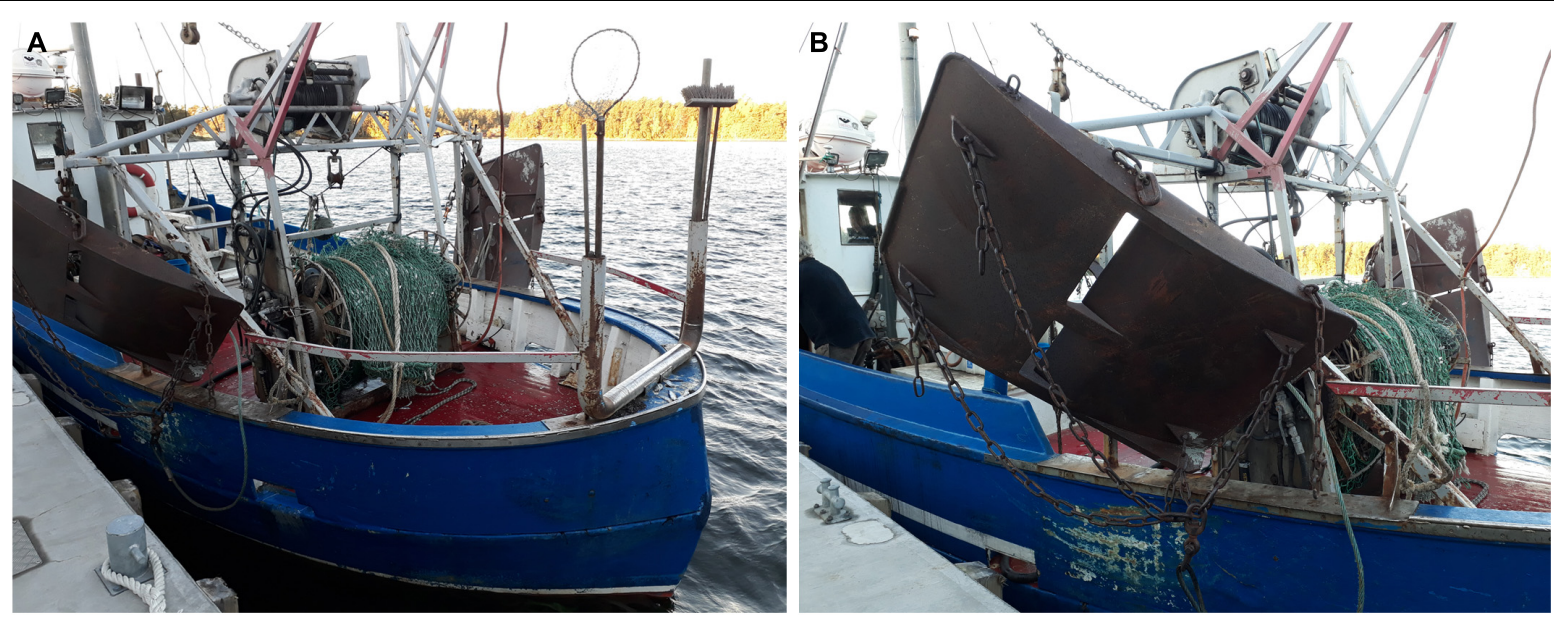

FIGURE 2 | (A) General view of the aft deck of the trawler showing the winched-in net with net floats visible and a trawl door hanging on each side of the boat; (B) one of the trawl doors (size c. $110 \times 160 \mathrm{~cm}$ ).

were taken, and an Acoustic Doppler Current Profiler (ADCP; Workhorse Mariner, $600 \mathrm{kHz}$ ) transect taken to ascertain water current speed and direction. The trawl was then set at $58^{\circ} 50.8215^{\prime} \mathrm{N}, 017^{\circ} 41.8905^{\prime} \mathrm{E}$, towed at a normal fishing speed of c. 2.5 knots in a SW to NE direction, and hauled at $58^{\circ} 49.6027^{\prime} \mathrm{N}, 017^{\circ} 39.5284^{\prime} \mathrm{E}$ (Figure 1), with an open codend. Stockholm University's R/V Electra followed behind the fishing boat, performing acoustic geophysical mapping of the seafloor and water column along the whole length of the trawl track with the multibeam echo sounder (Figure 1 and Supplementary Table 1). A distance of c. $300 \mathrm{~m}$ was maintained to ensure that the acoustic instruments measured just behind the end of the trawl net. The geophysical mapping methods are described in detail in section "Geophysical Mapping, Processing, and Analyses" and Supplementary Section 2.1).

Further CTD casts and water sampling were done $2 \mathrm{~h}, 20 \mathrm{~h}$, 3 days, and 4 days after trawling (Figure 1 and Supplementary Table 2) to measure the spread of the trawl-suspended sediment. Sediment samples were taken using a 4-core multicorer, 1 and 2 days after trawling, within the trawl track and c. $100 \mathrm{~m}$ away from the trawl track (Figure 1 and Supplementary Table 3). Bottom water current direction and speed were determined with ADCP along two transects $20 \mathrm{~h}$ and 3 days post-trawling (Supplementary Section 3.1). Four days after trawling, subbottom profiles were acquired with a penetrating echo sounder along the trawl track to characterize the underlying sediments (Supplementary Section 2.4).

\section{Geophysical Mapping, Processing, and Analyses}

High-resolution bathymetric and water column data were acquired using R/V Electra's hull-mounted Kongsberg EM2040 $0.4^{\circ} \times 0.7^{\circ}, 200-400 \mathrm{kHz}$, multibeam echo-sounder. Position, heading and attitude (heave, pitch and roll) data were received from a Kongsberg-Seatex Seapath 330+ Global Navigation Satellite System (GNSS), making use of both GPS and GLONASS satellites and an attached Seatex MRU5+ motion and reference sensor. The Seapath $330+$ capacity of applying real-Time Kinematic (RTK) positioning was used and corrections were imported from SWEPOS ${ }^{1}$. The Seapath $330+$ reported maximum ellipses of Estimated Position Error (EPE) on the order of $2-5 \mathrm{~cm}$ during the surveys. An AML sound velocity probe mounted near the multibeam transducers gave continuous readings of surface sound speed. In addition, a Valeport Mini SVP (Sound Velocity Profiler) was used to acquire sound speed profiles in the survey area.

Sub-bottom profiles were acquired using the hull-mounted Kongsberg Topas PS40, 24 channel, parametric sub-bottom profiler operating with primary and secondary frequencies of $35-45 \mathrm{kHz}$ and $1-10 \mathrm{kHz}$, respectively. The sub-bottom profiles shown were acquired using the system in chirp mode with a $1 \mathrm{~ms}$ long $2-10 \mathrm{kHz}$ pulse. This system also received positions from the Seapath $330+$.

The multibeam bathymetry data were cleaned and initially analyzed using the QPS QIMERA software (Version 2.1.0) ${ }^{2}$, where grids were produced representing the seafloor bathymetry with resolutions of $0.5 \times 0.5 \mathrm{~m}$ to $0.25 \times 0.25 \mathrm{~m}$. Multibeam backscatter was processed using QPS FMGT (Version 7.9.2) and the acoustic water column information with QPS FM Midwater (Version 7.9.0). The processed mapping data were subsequently imported to the Open Source Geographic Information System QGIS, version 3.10.0 A Coruña ${ }^{3}$, for further analyses and map making. The sub-bottom profiles were processed and displayed using software tools provided by the Geological Survey of Canada, courtesy of Bob Courtney.

The area was initially mapped with multibeam from 2 to 4 May 2018 (Figure 1), i.e., about 5.5 months before the trawling on 22 October the same year. The bathymetry data from October were adjusted by $2 \mathrm{~cm}$ to account for differences in seafloor bathymetry

\footnotetext{
${ }^{1}$ https://swepos.lantmateriet.se/

${ }^{2}$ https://www.qps.nl/

${ }^{3}$ http://qgis.osgeo.org
} 
and/or sea level between the two dates (see Supplementary Section 2.1 for details). The corrected bathymetric surface produced after trawling (October) was subtracted from the surface before the trawling (May) for two $6 \mathrm{~m}$-wide, $900 \mathrm{~m}$-long corridors along each of the door tracks. This produced a detailed map, where positive values indicated depressions and negative values piles of sediment on the seabed. The volume of the furrows and piles produced by the trawling was also calculated from these corridors. Ten $20 \mathrm{~m}$-long boxes along the track were identified as having the highest quality data and, of these, Boxes 2 and 7 were selected for detailed analyses of the dimensions of the trawl track features, since the small-scale topography in these two areas was most distinct, with between-survey differences close to $0 \mathrm{~m}$ outside the trawl marks.

The trawl track was re-mapped with multibeam on April 7,2020 , to investigate if the tracks still were visible in the seafloor or if they had been degraded by bottom processes, i.e., sedimentation, erosion, or bioturbation. This was followed by visual inspections by divers, as described below.

\section{Visual Inspection of the Trawl Tracks}

Four days after trawling (26 October 2018), a 25 m-long part of the track was inspected using a camera mounted on a BlueROV2 Remotely Operated Vehicle (ROV) equipped with an underwater positioning system linked to GPS (Figure 1). A second inspection was done on 7 April 2020 by divers in the same place as the 2019 ROV survey (Figure 1).

\section{CTD and Water Sampling}

CTD casts were taken using a Seabird 911+ (Seabird Scientific) down to $0.5 \mathrm{~m}$ above the bottom (m.a.b.), continuously measuring depth, salinity, temperature, and turbidity (postprocessing binned the data to every $0.25 \mathrm{~m}$ ). A Rosette sampler fitted with twelve $5 \mathrm{~L}$ Niskin bottles was used to take water samples at various distances above the seabed, with a focus on the bottom water (0.5-10 m.a.b.).

At each water depth, water for dissolved methane analysis was immediately collected directly through silicone tubes from the CTD rosette bottles into $100 \mathrm{~mL}$ serum bottles and allowed to overflow twice. One hundred microliters of a $50 \%$ zinc chloride $\left(\mathrm{ZnCl}_{2}\right)$ solution was added to stop all biological activity and the bottles immediately sealed with butyl rubber septa and crimped, ensuring no air bubbles were trapped.

The rest of the water sample was mixed well and different subsamples taken. A known volume (c. $1 \mathrm{~L}$ ) of water was filtered on a pre-weighed and pre-burnt $47 \mathrm{~mm}$ GF/F filter for quantification of suspended particulate matter (SPM) and particulate organic matter (POM). A further two samples were filtered in the same way for analysis of; (1) particulate carbon and nitrogen; and (2) particulate phosphorus. In between samples, funnels and filters were rinsed with $50 \mathrm{~mL}$ MilliQ water to remove any salt. All filters were frozen immediately at $-20^{\circ} \mathrm{C}$ in foil. Duplicate $10 \mathrm{~mL}$ water samples were filtered through a disposable $0.47 \mu \mathrm{m}$ filter into 2 vials for dissolved nutrient analysis $\left[\left(\mathrm{NO}_{3}{ }^{-}+\mathrm{NO}_{2}{ }^{-}\right)-\mathrm{N}, \mathrm{NH}_{4}{ }^{+}-\mathrm{N}, \mathrm{PO}_{4}{ }^{3-}-\mathrm{P}\right.$, hereafter referred to as $\mathrm{NO}_{\mathrm{x}}, \mathrm{NH}_{4}$, and $\mathrm{PO}_{4}$ ] and frozen immediately at $-20^{\circ} \mathrm{C}$. Twelve millilitres of water was filtered through a $0.2 \mu \mathrm{m}$ disposable filter into a vial for dissolved element analysis ( $\mathrm{Al}, \mathrm{Fe}$, $\mathrm{Mn}, \mathrm{P}, \mathrm{Ti}$ ) and $100 \mathrm{~mL}$ water was saved unfiltered in a factory clean plastic bottle for total element analysis. The vials and bottles were pre-filled with a volume of concentrated suprapure $\mathrm{HNO}_{3}$ equivalent to $1 \%$ of the sample volume. Both were kept $\operatorname{cool}\left(8^{\circ} \mathrm{C}\right)$ and dark. MilliQ blanks were taken for all these analyses.

\section{Sediment Sampling and Processing and Sediment Flux Measurements}

A multicorer (K.U.M. Umwelt und Meerestechnik Kiel), fitted with four acrylic core tubes [inner diameter (i.d.) $9 \mathrm{~cm}$, height $60 \mathrm{~cm}$ ] was used to take sediment cores. A total of 11 cores were taken $24 \mathrm{~h}$ after trawling at different locations within and outside the trawl track (Figure 1 and Supplementary Table 3), and sampled for a range of measurements (see below). Four further cores from the trawl door track and four from $100 \mathrm{~m}$ outside the trawl track (Figure 1 and Supplementary Table 3) were taken 2 days after trawling for $\mathrm{O}_{2}$ microprofiling and for nutrient flux incubations. In these eight cores, the overlying water was removed and collected in one container per station for later use in the incubations. Each core was subsampled using a smaller Plexiglas core tube (i.d. $4.6 \mathrm{~cm}$, length $30 \mathrm{~cm}$ ). These minicores were capped top and bottom with rubber stoppers, ensuring no air bubbles in the overlying water, and immediately placed in a dark cool box for transport to the laboratory within a few hours of collection.

Porewater samples were extracted from three cores at $1-5 \mathrm{~cm}$ intervals (closer intervals near the sediment surface) with rhizons (Rhizosphere Research Products) (Seeberg-Elverfeldt et al., 2005). The rhizons had been pre-treated for $2 \mathrm{~h}$ in $2 \mathrm{M}$ $\mathrm{HCl}$, followed by two rinses with deionized water for $2 \mathrm{~h}$ and final storage in deionized water. The overlying water was drained and rhizons were connected to $10 \mathrm{~mL}$ disposable plastic syringes via 3-way luerlock stopcocks and inserted through tight-fitting, predrilled holes in the sediment tubes. The first $\mathrm{mL}$ of pore water was discarded from the syringe. Then two samples of c. $1 \mathrm{~mL}$ porewater were collected in separate Eppendorf tubes for analysis of dissolved elements and dissolved nutrients. No more than $2 \mathrm{~mL}$ were collected from each core to prevent cross-contamination of adjacent intervals (Seeberg-Elverfeldt et al., 2005) and samples were stored frozen.

Three cores were used for measurements of porewater dissolved methane. A sediment sample of $2.5 \mathrm{~mL}$ was taken with a $3 \mathrm{~mL}$ cut-off syringe through the side of taped, pre-drilled core tubes at $2 \mathrm{~cm}$ intervals. The sample was directly transferred to a $20 \mathrm{~mL}$ serum vial containing $5 \mathrm{~mL} 5 \mathrm{M} \mathrm{NaCl}$, immediately closed with a thick septum and an aluminum crimp seal and shaken thoroughly to produce a slurry (Sawicka and Brüchert, 2017).

Four cores were sliced at $1 \mathrm{~cm}$ intervals down to $8 \mathrm{~cm}$ and thereafter $1 \mathrm{~cm}$ slices taken at $9-10 \mathrm{~cm}, 14-15 \mathrm{~cm}, 19-20 \mathrm{~cm}$, and $24-25 \mathrm{~cm}$ deep. Each slice was frozen in a separate ziplock bag for analysis of sediment porosity, organic carbon content and grain size.

Sediment microprofiling for $\mathrm{O}_{2}$ concentrations was conducted in two $4.6 \mathrm{~cm}$ i.d. cores using a Clark-type microelectrode (OX-50, Unisense), one core from the trawl track and one from 
outside the track. Three replicate microprofiles were carried out in each core. The microelectrode tip $(50 \mu \mathrm{m})$ was inserted directly inside each sediment core, while an air stone was bubbling air to ensure sufficient water mixing during the measurements. The sensor was calibrated using a two-point calibration procedure in $\mathrm{O}_{2}$ saturated bottom water and inside the sediment (zero reading). Oxygen penetration depth (OPD) was defined as the depth where $\mathrm{O}_{2}$ concentration was consistently $<1 \mu \mathrm{mol} \mathrm{L}^{-1}$.

The eight $4.6 \mathrm{~cm}$ i.d. cores were used for a nutrient flux incubation experiment. All cores were fitted with individual magnetic stirrers in the overlying water and placed uncapped in a temperature-controlled incubator at in situ temperature $\left(6^{\circ} \mathrm{C}\right)$ in the dark. The overlying water was carefully replaced with in situ bottom water, avoiding sediment resuspension, so that all cores were exposed to the same overlying water. After an $8 \mathrm{~h}$ stabilization period, a $15 \mathrm{~h}$ incubation was performed to estimate nutrient and oxygen fluxes across the sediment-water interface. Dissolved oxygen measurements and water samples for nutrients were taken immediately prior to capping the cores for the incubation and immediately after the stoppers were removed. Oxygen was measured directly using a microelectrode (OX-500, Unisense), calibrated with 0 and $100 \% \mathrm{O}_{2}$-saturated in situ bottom water (bubbled with $\mathrm{N}_{2}$ or air, respectively). Water samples for nutrients were filtered on a GF/F filter and frozen prior to analysis of $\mathrm{NO}_{\mathrm{x}}, \mathrm{NH}_{4}$ and $\mathrm{PO}_{4}$. Net solute fluxes were calculated from the difference between final and initial concentrations according to Bonaglia et al. (2013). Positive values represent effluxes while negative values represent sediment uptake.

\section{Sample Analysis}

\section{Water and Porewater Sample Analyses}

Filters for SPM were dried at $60^{\circ} \mathrm{C}$ and reweighed to obtain the dry weight (DW) of SPM per filter. They were then burnt at $500^{\circ} \mathrm{C}$ and reweighed to obtain the mass of particulate organic matter (POM) per filter by loss on ignition. SPM and POM were standardized to $\mathrm{mDWW} \mathrm{L}^{-1}$, based on the water volume filtered.

Particulate $\mathrm{C}$ and $\mathrm{N}$ on filters were determined with a Thermo Scientific Flash 2000 elemental analyzer after combustion at $950^{\circ} \mathrm{C}$ and particulate $\mathrm{P}$ with a segmented flow autoanalyzer system (ALPKEM, Flow Solution IV) after combustion at $500^{\circ} \mathrm{C}$ and persulfate digestion. Precision was 8,15 , and $7 \%$ for C, N, and $\mathrm{P}$, respectively.

Porewater nutrients were analyzed spectrophotometrically following appropriate dilution with artificial seawater of $6 \%$ salinity. Dissolved nitrate was analyzed according to Schnetger and Lehners (2014), dissolved inorganic phosphate following Koroleff (1983), and dissolved ammonium following Bower and Holm-Hansen (1980). The analytical precision, based on replicate analyses, was $5 \%$.

Dissolved concentrations of $\left(\mathrm{NO}_{2}{ }^{-}+\mathrm{NO}_{3}^{-}\right)-\mathrm{N}, \mathrm{NH}_{4}{ }_{-}^{-}$ $\mathrm{N}$ and $\mathrm{PO}_{4}{ }^{3-}-\mathrm{P}$ in bottom water were determined on a segmented flow autoanalyzer system (ALPKEM, Flow Solution IV). Precision was $\pm 4 \%$ for $\mathrm{NO}_{\mathrm{x}}$, approximately $\pm 5 \%$ for $\mathrm{NH}_{4}$, depending on concentration, and $\pm 7 \%$ for $\mathrm{PO}_{4}$.
Element analyses of filtered and non-filtered water samples (i.e., dissolved and total concentrations) and porewater samples were done with an ICP-OES, Thermo ICAP Duo 6500. Samples were mostly run undiluted but pore water samples were sometimes diluted before analysis because of small sample volumes (dilution 1:5). Samples were thereafter run in both axial and radial mode having a small concentric glass spray chamber and a seaspray nebulizer using an integration time of $30 \mathrm{~s}$ to get high sensitivity. The seaspray nebulizer has high tolerance to particulates, typically up to $75 \mu \mathrm{m}$. Results from analyses were within $\pm 5 \%$ when comparing with a certified standard, NIST 1640a. Particulate element concentrations were calculated as the difference between total concentration (non-filtered) and dissolved (filtered) concentration for each sample.

For analysis of dissolved methane in water samples, $10 \mathrm{~mL}$ of the water was replaced by helium gas at ambient pressure. The bottles were placed horizontally on a shaker table and equilibrated while shaking overnight at room temperature. For analysis, $3 \mathrm{~mL}$ of the headspace were replaced with an equivalent amount of a $6 \% 0 \mathrm{NaCl}$ solution maintaining the solubility of methane. The gas sample was injected on a Shimadzu GC-8A with flame ionization detector. The instrument was calibrated with synthetic gas standards from Air Liquide (11.414 ppmv and $5.003 \mathrm{ppmv} \mathrm{CH}_{4}$ ). The dissolved methane concentration in the water sample was calculated following Bange et al. (2010) from the sum of the methane mole fraction in the headspace and the mole fraction of dissolved methane.

To analyze porewater methane, each sediment sample was shaken and $5 \mathrm{~mL}$ of a saturated $\mathrm{NaCl}$ brine solution was injected into the sample vial to displace $5 \mathrm{~mL}$ gas into the sampling syringe. The $\mathrm{CH}_{4}$ measurements were carried out on a SRI gas chromatograph (GC) with a flame ionization detector (FID) (SRI 8610C) with $\mathrm{N}_{2}$ as carrier gas. $\mathrm{CH}_{4}$ standards of 100,1,000, and 10,000 ppm (Air Liquide) were used for calibration. The concentration of methane $\left(\mathrm{mmol} \mathrm{L}^{-1}\right)$ in a sediment sample was calculated according to Equation 2 in Supplementary Section 3.3.1.

\section{Sediment}

The wet weight, dry weight and ash-free dry weight of $5 \mathrm{~mL}$ of each wet sediment sample (depth layer) were determined by drying at $60^{\circ} \mathrm{C}$ for at least $24 \mathrm{~h}$ and then combusting at $500^{\circ} \mathrm{C}$ for $4 \mathrm{~h}$. Porosity was calculated as the volume proportion of porewater in $5 \mathrm{~mL}$ wet sediment (wet sediment weight minus dry sediment weight, water density assumed to be $1 \mathrm{~g} \mathrm{~mL}^{-1}$ ). Organic matter content was calculated as the difference between ash-free dry weight and dry weight, expressed as \% of dry weight. Sediment bulk density (gDW $\mathrm{mL}^{-1}$ ) was calculated as (1-porosity) $\times 2.65$, where 2.65 is the assumed sediment density. Sediment grain size analysis was performed on wet untreated sediment with a Malvern Mastersizer.

Chlorophyll was extracted from each wet sediment slice by taking triplicate subsamples of $1 \mathrm{~cm}^{3}$ using a cut-off syringe, adding $9 \mathrm{~mL}$ of $95 \%$ ethanol to each and leaving the samples overnight in the fridge. After centrifugation $(4,000 \mathrm{rpm}$ for $5 \mathrm{~min}$ ), chlorophyll in the supernatant was measured at 663 and 
$750 \mathrm{~nm}$ using a Shimadzu spectrophotometer and chlorophyll concentration calculated according to HELCOM (1988).

\section{Calculations and Statistics}

All statistics [analysis of variance (ANOVA), principle component analysis (PCA), multiple correlations] and contour plots were done with Statistica v. 13.3. Further details of the calculations are presented in the Supplementary Sections 2.2, 2.3, 3.2.1, 3.3.1, but a brief summary is given here.

\section{Area, Volume, and Mass of Disturbed Sediment on the Seabed}

Spatial dimensions of the trawl disturbance, depth of penetration of the trawl doors and sediment volumes displaced were estimated from analysis of multibeam data (see Supplementary Sections 2.1 and 2.2) and, together with site data on sediment porosity, used to calculate total volumes and masses of sediment disturbed by the fishing gear. Details are provided in Supplementary Section 2.3, but a summary is given here.

Volumes of sediment excavated by the trawl doors (=furrows) and deposited as sediment piles at the sides of these furrows, expressed per $\mathrm{m}$ of single furrow, as well as average door penetration depth $(9 \mathrm{~cm})$ were obtained from the multibeam data analysis (see Figure 3 and section "Physical Impact of Trawling on the Seabed"). Disturbance between the trawl doors was assumed to be caused by both groundgear and sweeps (as in Eigaard et al., 2016). Volumes of sediment disturbed by the groundgear and sweeps were calculated from the distance between the trawl door tracks (obtained from the multibeam data) and a depth of disturbance of $2 \mathrm{~cm}$, since groundgear tracks were clearly visible in ROV images (Figure 4) but rarely seen with the multibeam which has a vertical resolution of $c$. $2 \mathrm{~cm}$ (see section "Physical Impact of Trawling on the Seabed" and Supplementary Section 2.3). Depth of disturbance of the sweeps was also taken as $2 \mathrm{~cm}$ (consistent with the groundgear and Eigaard et al., 2016). Sediment volumes were expressed per $\mathrm{m}$ or $\mathrm{m}^{2}$ of the whole trawl track, based on track dimensions of $1.4 \mathrm{~m}$ for each trawl door furrow and $33.4 \mathrm{~m}$ between these furrows, obtained from multibeam data. Sediment volumes were also converted to $\mathrm{kg}$ dry weight $(\mathrm{kgDW})$ per $\mathrm{m}$ or $\mathrm{m}^{2}$, using a sediment density of 0.44 or $0.52 \mathrm{gDW} \mathrm{mL} \mathrm{m}^{-1}$ (=average of top 2 or $9 \mathrm{~cm}$ from four sediment cores taken in the area). The relative contribution of the trawl doors and groundgear was also estimated, based on the proportion of the sediment area or volume disturbed by these two components.

\section{Suspended Sediment and Particulate Substances}

The total amount of sediment suspended per $\mathrm{m}$ of trawl track was calculated from the CTD turbidity data (in NTU; Nephelometric Turbidity Unit), converted to $\mathrm{mgDW} \mathrm{L}^{-1}$ using the relationship obtained from filtered water samples [SPM

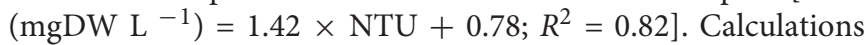
were based on a $1 \mathrm{~m}$-wide swathe across the trawl track and the corresponding $1 \mathrm{~m}$-wide "downstream" water volume, divided horizontally and vertically into compartments according to the depth and position of $2 \mathrm{~h}$ post-trawling measurements. Thus, data from $0.5,2.5,5,7.5$, and 10 m.a.b., and $0,100,250$, and
$550 \mathrm{~m}$ from the trawl track were used, i.e., the water volume that was known to include the suspended sediment plume. The mass of SPM in each compartment was calculated and background turbidity, obtained from the average of the two CTD casts $3 \mathrm{~h}$ prior to trawling, was subtracted for each water depth.

The resulting masses were summed to obtain the total excess mass of sediment in the downstream sediment plume. The total amounts of particulate elements $(\mathrm{C}, \mathrm{N}, \mathrm{P}, \mathrm{Al}, \mathrm{Fe}, \mathrm{Mn}, \mathrm{Ti})$ in the sediment plume were also estimated by multiplying the mass of SPM in each water compartment by the ratios of element to SPM concentrations measured in the same water samples $2 \mathrm{~h}$ after trawling. $\mathrm{Al}$ and $\mathrm{Ti}$ were selected as unreactive inorganic particle tracers, $\mathrm{Fe}$ and $\mathrm{Mn}$ as redox sensitive reactive elements, $\mathrm{N}$ and $\mathrm{P}$ as nutrients and $\mathrm{C}$ as a tracer of organic matter. Results were expressed as $\mathrm{kgDW} \mathrm{m}^{-1}$ or $\mathrm{kgDW} \mathrm{m}^{-2}$ trawl track and the relative contributions of the trawl doors and groundgear to this suspension was also estimated, based on the relative proportions of these components to the seabed disturbance (see section "Area, Volume, and Mass of Disturbed Sediment on the Seabed").

\section{Dissolved Substances (Al, Fe, Mn, Ti, Dissolved Nutrients, Methane)}

Since elevated concentrations of several dissolved substances were seen in the bottom water after trawling, most likely from mixing of sediment porewater into the water column, we calculated the potential amount of dissolved substances that could be released from the disturbed sediment in the trawl track. A depth of sediment disturbance of $9 \mathrm{~cm}$ in the door tracks and $2 \mathrm{~cm}$ in the groundgear tracks was used (see section "Area, Volume, and Mass of Disturbed Sediment on the Seabed"). The average porewater concentrations of $\mathrm{Al}, \mathrm{Fe}, \mathrm{Mn}, \mathrm{Ti}, \mathrm{NH}_{4}, \mathrm{NO}_{\mathrm{x}}$, $\mathrm{PO}_{4}$, and $\mathrm{CH}_{4}$ ) in the top 2 or $9 \mathrm{~cm}$ of sediment was determined from three sediment cores and the total amount (mg) of each present in a $1 \mathrm{~m}$ wide swathe across the entire trawl track calculated, taking into account the relative proportions of the groundgear and door tracks and assuming a sediment porosity of 0.84 or 0.80 (average of upper 2 or $9 \mathrm{~cm}$ from four other sediment cores). Overlying water concentrations were then calculated as the sum of background concentrations (average of two pretrawl sample profiles) and the released porewater, assuming the entire porewater inventory was released into the bottom $0.5 \mathrm{~m}$ of water immediately over the trawl track. The potential porewater contribution to this bottom water was expressed as a \% of the total concentration.

We also calculated to what degree porewater mobilized from sediment could contribute to measured dissolved concentrations in the bottom water $2 \mathrm{~h}$ after trawling. Calculations were performed assuming that the porewater inventory was diluted into an adjacent bottom water volume $5 \mathrm{~m}$ deep and up to $550 \mathrm{~m}$ away from the track (i.e., the transect for which we had actual measurements). The calculated porewater addition was compared to average concentrations measured at three stations $2 \mathrm{~h}$ post-trawling, up to 5 m.a.b. and $550 \mathrm{~m}$ away, and again expressed as \% of that water concentration. For methane, data from $20 \mathrm{~h}$ post-trawling were used. Lastly, ratios of measured 
post-trawl: pre-trawl water concentrations were calculated for different distances from the track and heights above the seabed.

\section{Relationships Between Components of the Sediment Plume Over Space and Time}

To explore the relationships and potential correlations between the different elements in the water column and whether, or how, their spatial distribution could be related to the suspended sediment plume (SPM, or the inorganic or organic fraction of SPM), two PCAs were performed; one for particulate substances and one for dissolved substances (see Supplementary Sections 3.2.2 and 3.3.2). SPM, organic matter concentration, inorganic matter concentration, time, distance from trawl track and meters above bottom (m.a.b.) were included as supplementary variables and superimposed on the PCA plots. The supplementary variables' relationships with the element and nutrient concentrations were determined using separate multiple correlation analyses.

\section{Comparison of Sediment Fluxes}

Differences in each sediment flux $\left(\mathrm{NH}_{4}, \mathrm{NO}_{\mathrm{x}}, \mathrm{PO}_{4}, \mathrm{O}_{2}\right)$ between trawled samples and untrawled samples were compared using a one-way ANOVA. Normality of the data was assessed visually using normal probability plots of the residuals and homogeneity of variance tested with the Cochran's C test. Since Cochran's test was not significant in all cases and there were no major deviations from normality, the ANOVAs were performed on untransformed data.

\section{RESULTS}

\section{Physical Impact of Trawling on the Seabed}

The tracks created by the trawl doors comprised two regular rows of pits with sediment piles on the sides, rather than smooth consistent furrows (Figure 3). The piles of displaced sediment were particularly pronounced on the inner side of the furrow (Figures 3, 4C).

Using the areas with best quality multibeam data (Boxes 2 and 7, Figure $3 \mathbf{b}$ ), the mean width of the furrows was $1.6 \mathrm{~m}$ and ranged from 6 to $12 \mathrm{~cm}$ deep. In the entire analyzed corridor shown in Figure 3b, the maximum furrow depth was $16 \mathrm{~cm}$. The sediment piles on the inner sides of the trawl doors were higher than on the outer side of the track and were 1.4-1.9 m wide and up to $8 \mathrm{~cm}$ high in the whole corridor. These values should be seen as minimum measures of the average maximum dimensions as the measurements are made between the $-2 \mathrm{~cm}$ contours.

In the area between the two trawl door tracks, shallow parallel depressions were seen in ROV images (Figure 4B). These were produced by the rollers on the groundgear moving over the seabed and had a depth of c. $2 \mathrm{~cm}$, since they were only occasionally visible in the multibeam data which has a vertical resolution in the order of $\pm 0.1 \%$ of the water depth, i.e., $\pm 2 \mathrm{~cm}$ in $20 \mathrm{~m}$ water depth.

The furrows of the trawl door tracks were estimated from multibeam bathymetry to occupy volumes of $0.24-0.34 \mathrm{~m}^{3} \mathrm{~m}^{-1}$ of track while the sediment piles range between 0.14 and $0.24 \mathrm{~m}^{3}$ $\mathrm{m}^{-1}$ (Table 1). The relative contributions of the groundgear and trawl doors to the sediment disturbance were estimated; per $\mathrm{m}^{2}$ disturbed, the doors have a larger impact (by a factor of c. 5-6). However, the total volume or mass disturbed for every $m$ the trawl is dragged is potentially greater (factor of c. 2-3) for the groundgear, since the area affected comprises a relatively large proportion of the total track ( $92 \%$ of the total area and $70 \%$ of the total disturbed volume) (Supplementary Section 2.3). A total of about $1 \mathrm{~m}^{3}$ or $12 \mathrm{~kg}$ sediment was therefore disturbed per $\mathrm{m}$ of seabed trawled.

The trawl tracks may also be visible with sub-bottom profiling, since the locations of the trawl tracks in sub-bottom profile SBP 805 coincide with acoustically transparent spots (Supplementary Figure 2), which commonly appear where layered sediments are disturbed. Although several other similar spots are visible along the profile, it seems more than coincidental that these exactly match the trawl track locations. The vertical resolution of the subbottom profiles is on the order of $10-20 \mathrm{~cm}$, so it is not impossible that the tracks, with their vertical topography of c. $20 \mathrm{~cm}$, might be visible in this way.

The re-survey of the trawl tracks in April 2020, i.e., 18 months after they were formed, showed that the tracks were still preserved in the seafloor and clearly visible in multibeam images (Supplementary Figure 4). However, the backscatter signal was much fainter, and divers could not see the tracks.

\section{Spatial and Temporal Patterns in Particulate Substances in the Water Column}

During the week of the field experiment, the water column did not show strong stratification, but there were two water masses: an overlying stable layer (c. $7.5^{\circ} \mathrm{C}$, salinity c. $7 \mathrm{psu}$ ) down to about 10-20 m water depth; and an underlying layer where temperature and salinity decreased steadily to c. $5.5^{\circ} \mathrm{C}$ and c. 7.3 psu at $0.5 \mathrm{~m}$ above the seafloor. There was a tendency for the surface layer to extend slightly deeper further to the SE. The depth of the overlying layer also increased during the week from c. $10 \mathrm{~m}$ to c. $20 \mathrm{~m}$, particularly between 1 and 3 days after trawling.

Bottom water currents and speeds were spatially and temporally variable during the week. Current speeds were generally slow $\left(<6 \mathrm{~cm} \mathrm{~s}^{-1}\right)$ and, in the area from the trawl track to where the suspended sediment was measured, the general direction of flow was between SW and SE, depending on the exact position, water depth and date (Figure 1 and Supplementary Figure 7).

\section{Particulate Substances in the Bottom Water}

Multibeam acoustic imagery of the water column clearly showed sediment suspension during trawling (Figure 5), both by the trawl doors and from the groundgear. Two hours after trawling, the turbid plume was detected over the trawl track and 250$550 \mathrm{~m} \mathrm{SE}$ of the track (Figure 6A). Given that bottom current speeds were a maximum of c. $6 \mathrm{~cm} \mathrm{~s}^{-1}$ during this period (Supplementary Figure 7), this agrees well with theoretical maximum transport of about $430 \mathrm{~m}$. Maximum turbidity was 

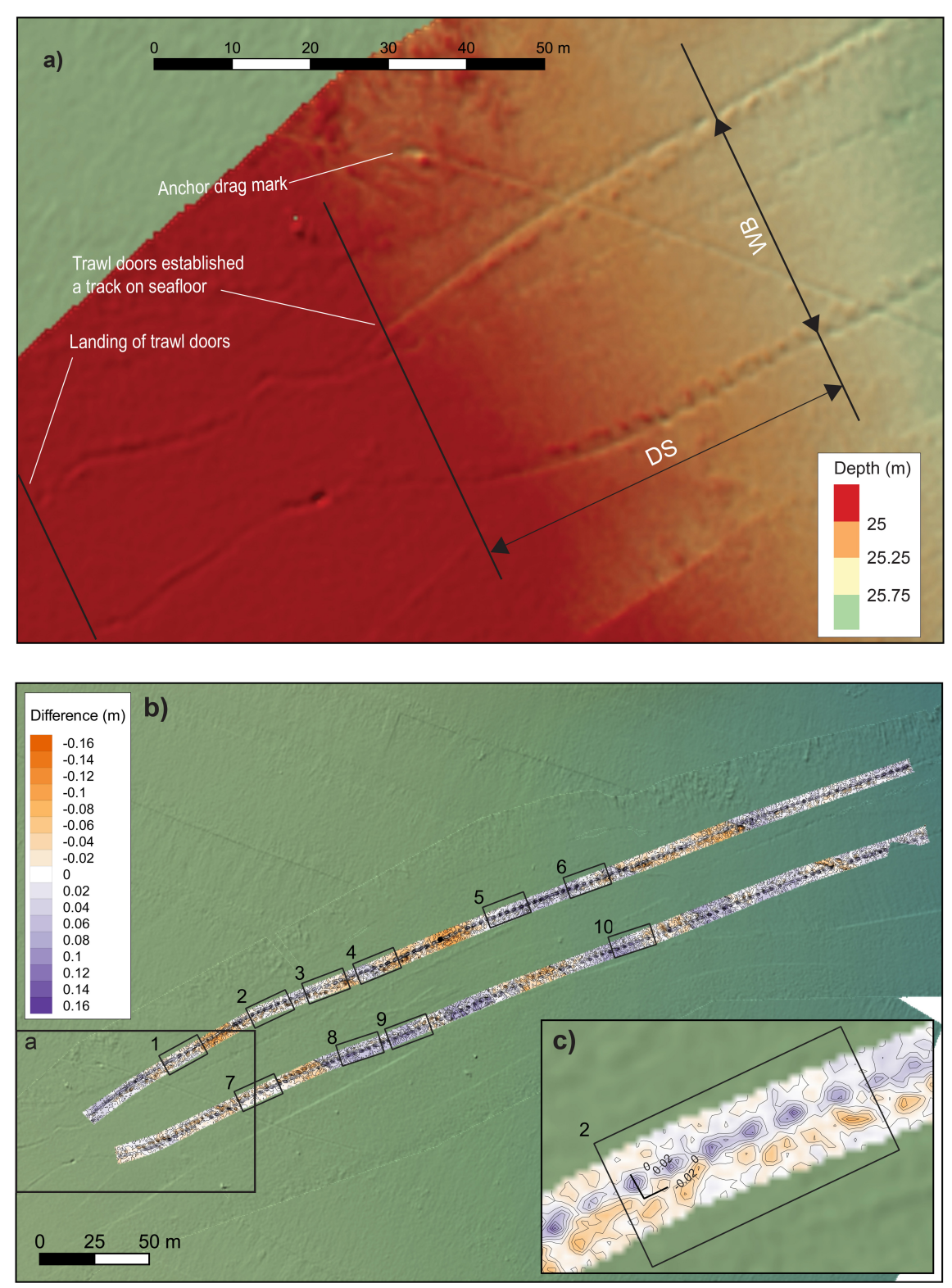

FIGURE 3 | Detailed maps showing the tracks from the trawl doors visible in the multibeam bathymetry. (a) Shaded relief of the multibeam bathymetry showing where the two trawl doors landed on the seafloor and after about $50 \mathrm{~m}$ begun to establish a regular trawl path. DS is the distance between measurements made to establish the distance between the two trawl doors. The first measurement was made $50 \mathrm{~m}$ after the doors began to establish a regular path (DS = 50). Thereafter, measurements were made every $100 \mathrm{~m}$ (Supplementary Table 4). The anchor drag mark was 5.5 months old at the time this image was taken. (b) The depth difference between the multibeam surveys before and after trawling, along two c. $6 \mathrm{~m}$ wide corridors around the trawl tracks (North and South corridors in text). The ten $10 \times 20$ m boxes were used for quantification of sediment displacement (see Supplementary Section 2.2). (c) Detail showing Box 2. Contours with an interval of $0.02 \mathrm{~m}$ are shown, with the 0 and $0.02 \mathrm{~m}$ contours labeled. The legs of the $\mathrm{L}$ shaped scale are $2 \mathrm{~m}$ long. In (b,c) blue shading indicates furrows (positive values compared to surrounding seabed) and orange displaced sediment piles (negative values).

4.1 NTU at 0.5 m.a.b. (cf. 3.0 NTU pre-trawling) and 2.9 NTU at 7.5 m.a.b. (cf. 1.1 NTU pre-trawling), i.e., an increase of up to $1.8 \mathrm{NTU}$ (Supplementary Table 6). The following day (20 h post-trawling), the plume was detected at least $500 \mathrm{~m}$ away from the track, following the general current direction, but had not decreased in turbidity (Figure 6B). Since the highest turbidity at $+20 \mathrm{~h}(4.3 \mathrm{NTU})$ was measured at $550 \mathrm{~m}$ from the track, we can conclude that we did not capture the entire plume with our sampling. Three days after trawling, the remnants of the plume were detectable $1.1 \mathrm{~km}$ away, although turbidity was lower at that distance (maximum of c. $2.5 \mathrm{NTU}$ ) and the sediment appeared to have settled out to form a thinner turbid bottom layer (Figure 6C). Again, given the current speeds in the area, this transport distance is entirely feasible. Turbidity was still high (>4 NTU at 0.5-1 m.a.b.) over the trawl track. Elevated turbidity was also detected several hundred meters NW of the track after 

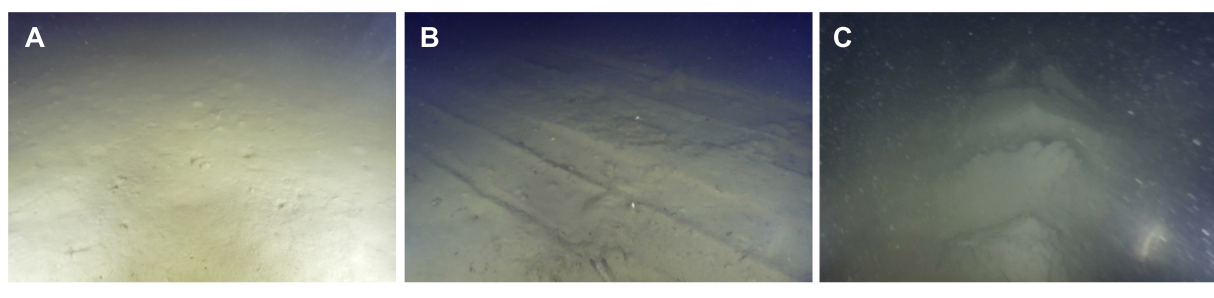

FIGURE 4 | ROV images showing (A) undisturbed sediment, (B) shallow parallel tracks formed by the rubber discs on the groundgear, (C) piles of sediment displaced by the trawl doors. See Figure 1 for location.

$20 \mathrm{~h}$ and 3 days (Figures 6B,C), probably due to variable bottom currents during the period of study (Figure 1 and Supplementary Figure 7). Using the site-specific NTU to SPM conversion, the maximum concentration of suspended matter was $6.9 \mathrm{mgDW}$ $\mathrm{L}^{-1}$, measured $20 \mathrm{~h}$ after trawling, $550 \mathrm{~m}$ from the trawl track.

Concentrations of particulate $\mathrm{Al}, \mathrm{Fe}, \mathrm{Mn}$, and $\mathrm{Ti}$ strongly co-varied with each other and with concentrations of SPM and inorganic matter, reflecting the overall trends in turbidity (Supplementary Figure 9 and Supplementary Table 7). Particulate $\mathrm{P}$, and to a lesser extent $\mathrm{N}$, also co-varied with this group of elements. Concentrations of all elements except $\mathrm{Ti}$, as well as SPM and inorganic matter, were weakly negatively correlated (coefficients -0.11 to -0.43 ) with time since trawling, and all except $C$ were negatively correlated $(-0.30$ to -0.49$)$ with height above the seabed. There were no clear relationships with distance from the trawl track (see Supplementary Table 7), probably because this relationship is not linear as the plume likely moves as a water body that slowly disintegrates and diminishes.

\section{Total Amount of Suspended Sediment and Particulate Matter}

The total amount of sediment suspended was estimated as $9.5 \mathrm{~kg}$ per $\mathrm{m}$ of trawl track (i.e., a $1 \mathrm{~m}$ swathe across the entire $36.2 \mathrm{~m}$ width of the track) or $0.26 \mathrm{~kg} \mathrm{~m}^{-2}$. The relative contributions of

TABLE 1 | Summary of estimated sediment volumes and masses disturbed and displaced during trawling, based on multibeam measurements.

\begin{tabular}{|c|c|c|c|c|}
\hline & $\begin{array}{c}\mathrm{m}^{3} \mathrm{~m}^{-1} \text { of } \\
\text { track }\end{array}$ & $\begin{array}{l}\text { kgDW m-1 } \\
\text { of track }\end{array}$ & $m^{3} m^{-2}$ & $k g D W m^{-2}$ \\
\hline $\begin{array}{l}\text { Sediment } \\
\text { excavated by doors } \\
\text { (furrows) }\end{array}$ & $0.24-0.34$ & $125-177$ & $0.09-0.12^{a}$ & $44.5-63.1^{\mathrm{a}}$ \\
\hline $\begin{array}{l}\text { Sediment displaced } \\
\text { by doors into } \\
\text { sediment piles }\end{array}$ & $0.14-0.24$ & $73-125$ & $0.05-0.09^{a}$ & $26.0-44.5^{a}$ \\
\hline $\begin{array}{l}\text { Sediment disturbed } \\
\text { by groundgear }\end{array}$ & 0.67 & 291 & $0.02^{b}$ & $8.7^{b}$ \\
\hline $\begin{array}{l}\text { Sediment disturbed } \\
\text { by groundgear plus } \\
\text { doors }^{c}\end{array}$ & $0.91-1.01$ & $472-524$ & $\begin{array}{l}0.025- \\
0.028^{d}\end{array}$ & $11.5-12.9^{d}$ \\
\hline
\end{tabular}

Ranges are from using the two average values from the North and South corridors. a values are per $m^{2}$ of furrow.

${ }^{b}$ Values are per $m^{2}$ of central area of the track (i.e., disturbed by groundgear).

c Sum of groundgear and furrows.

${ }^{d}$ Values are per $\mathrm{m}^{2}$ whole trawl track (furrows plus central area). the trawl doors and groundgear were estimated as 2.9 and $6.6 \mathrm{~kg}$ $\mathrm{m}^{-1}$, respectively (Table 2 ). However, per $\mathrm{m}^{2}$, suspension was more than five times higher from the door furrows than from the groundgear (1030 and $199 \mathrm{~g} \mathrm{~m}^{-2}$, respectively; Table 2). The same was seen for particulate C, N, P, Fe, Mn, and Al (Table 2).

\section{Effects on Physical and Biogeochemical Sediment Properties}

Sediment profiles of porosity, organic carbon content, mean particle size and chlorophyll all suggested physical disturbance of the surface 3-5 cm in the trawl track (Supplementary Figure 5). Profiles of dissolved substances (e.g., Fe, Mn, nutrients, and dissolved methane) in the porewater also indicated disruption of the biogeochemistry of the surface sediment (Supplementary Figure 6). For several substances (e.g., chlorophyll, methane, porosity), these profiles confirm the removal or displacement of the surface sediment, and thus the apparent upward shift of these profiles compared to undisturbed sediment. The lack of a consistent type of disturbance across all cores is probably due to their exact positions relative to different features of the track.

\section{Effects on Dissolved Substances in the Bottom Water \\ Spatial and Temporal Trends in Concentrations of Dissolved Substances}

Two hours after trawling there was an increase in dissolved nutrients $\left(\mathrm{NH}_{4}, \mathrm{NO}_{\mathrm{x}}, \mathrm{PO}_{4}\right.$, total $\left.\mathrm{N}\right)$ and $\mathrm{Mn}$, up to $550 \mathrm{~m}$ away from the trawl track and up to c. 5 m.a.b.; Figure 7 and Supplementary Table 9). All the dissolved nutrients, together with $\mathrm{Mn}$, strongly co-varied (Supplementary Figure 10) and positively correlated with SPM, inorganic particulate matter and, to a lesser degree, POM (coefficients mostly $>0.7$; Supplementary Table 8). They were also negatively correlated with distance from the trawl track (coefficients c. 0.75) and with height above the seabed (coefficients c. 0.45-0.5) (Supplementary Table 8). In contrast, dissolved $\mathrm{Al}, \mathrm{Fe}$, and $\mathrm{Ti}$ tended to decrease in concentration after trawling close to the trawl track and in the bottom $0.5-1 \mathrm{~m}$ (Figure 7 and Supplementary Table 9). These elements covaried (Supplementary Figure 10) but were weakly negatively correlated with SPM, inorganic matter and POM and weakly positively correlated with distance and height over the seabed (Supplementary Table 9). The patterns visible $2 \mathrm{~h}$ after trawling were no longer visible after $20 \mathrm{~h}$. 

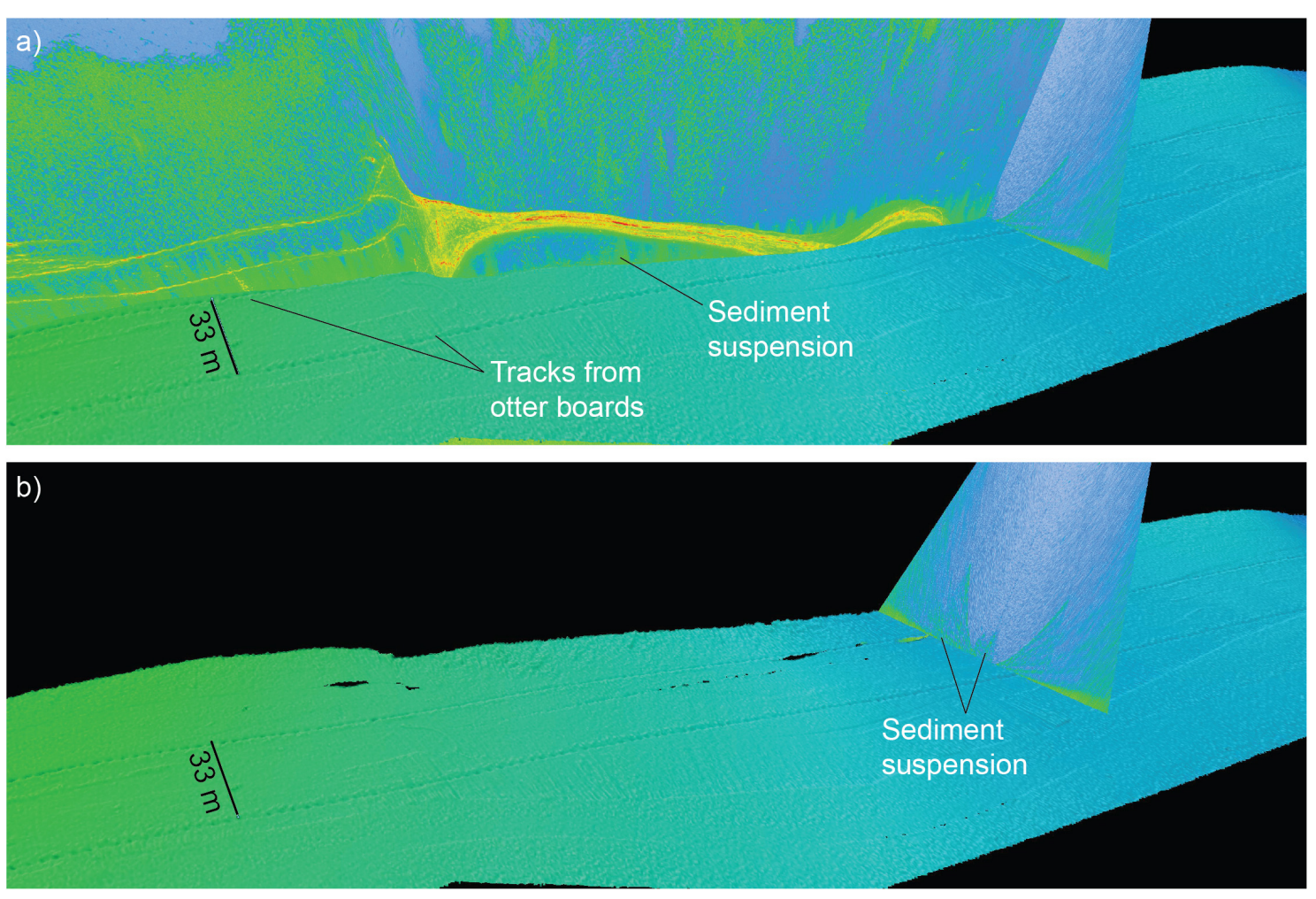

FIGURE 5 | 3D-view of acquired multibeam midwater imagery. (a) Stacked curtain of 256 beams that shows sediments being suspended during the trawling. The bright yellow/orange feature is the trawl net. The fan-view of the stacked beams is shown alone without the along-track curtain in (b) and reveals suspension from the groundgear.

Two hours after trawling, concentrations of dissolved methane in the water were c. $40 \mathrm{nmol} \mathrm{L}^{-1}$ up to c. 5 m.a.b. and several hundred meters SE of the track (Figure 8A). After $20 \mathrm{~h}$, concentrations had increased to nearly $60 \mathrm{nmol} \mathrm{L} \mathrm{L}^{-1}$ (Figure 8B) and were elevated much further away from the track and further above the seabed. Concentrations over the track 34 days after trawling were around $20 \mathrm{nmol} \mathrm{L}^{-1}$, which agrees with other typical measurements of $10-20 \mathrm{nmol} \mathrm{L}^{-1}$ in the area (unpublished data).

\section{Potential Contribution of Porewater to Bottom Water}

We evaluated if porewater release could account for the trends described above. If the entire porewater inventories from the top sediment layer in the trawl track were released directly into the bottom $0.5 \mathrm{~m}$ of water above the track, average bottom water concentrations could comprise up to c. $90 \%$ porewater (e.g., for $\mathrm{Fe}, \mathrm{NH}_{4}$ ), i.e., an increase in concentration by up to a factor of 14 , depending on the substance and the water depth (Table 3A). If the same porewater inventory was dispersed into the bottom $5 \mathrm{~m}$ of water and up to $550 \mathrm{~m}$ downstream (i.e., the volume where elevated concentrations were measured after 2 h; Figure 7), the excess element concentrations would represent up to only a few percent of the dissolved concentrations measured (Table 3B). Note, however, that these calculations were based on average concentrations across the area and do not account for the spatial heterogeneity in concentrations, as seen in Figures 7, 8.

\section{Nutrient and Oxygen Fluxes}

Two days after trawling, fluxes of nutrients from and oxygen to the sediment were lower in trawled sediments compared to the controls; these differences were significantly different for $\mathrm{O}_{2}$ $\left[F_{(1,6)}=8.73, p=0.025\right]$ and $\mathrm{NO}_{\mathrm{x}}\left[F_{(1,6)}=16.12, p=0.007\right]$ (Figure 9). Microsensor profiling showed that trawled sediments had significantly higher oxygen penetration depth $(5.3 \pm 0.2 \mathrm{~mm})$ than control sediments $(4.3 \pm 0.1 \mathrm{~mm})\left[F_{(1,}, 4\right)=15.25$, $p=0.017]$ (Figure 10).

\section{DISCUSSION}

In this study, we quantified the trawling-induced displacement and suspension of sediment and the related changes to benthic biogeochemistry by taking a range of field measurements after the single passage of a small otter trawl. We demonstrated short term local releases of dissolved substances (hours, a few hundred meters) and longer term (days) and larger scale $(\mathrm{km})$ suspension of particulate matter and substances. Physical disturbance of the seabed was clear and remained for at least 18 months.

\section{Physical Displacement of Sediment on the Seafloor}

The general appearance and dimensions we describe here, of deeper paired door tracks, c. 1.2-1.6 m wide and 6-12 cm (max. 

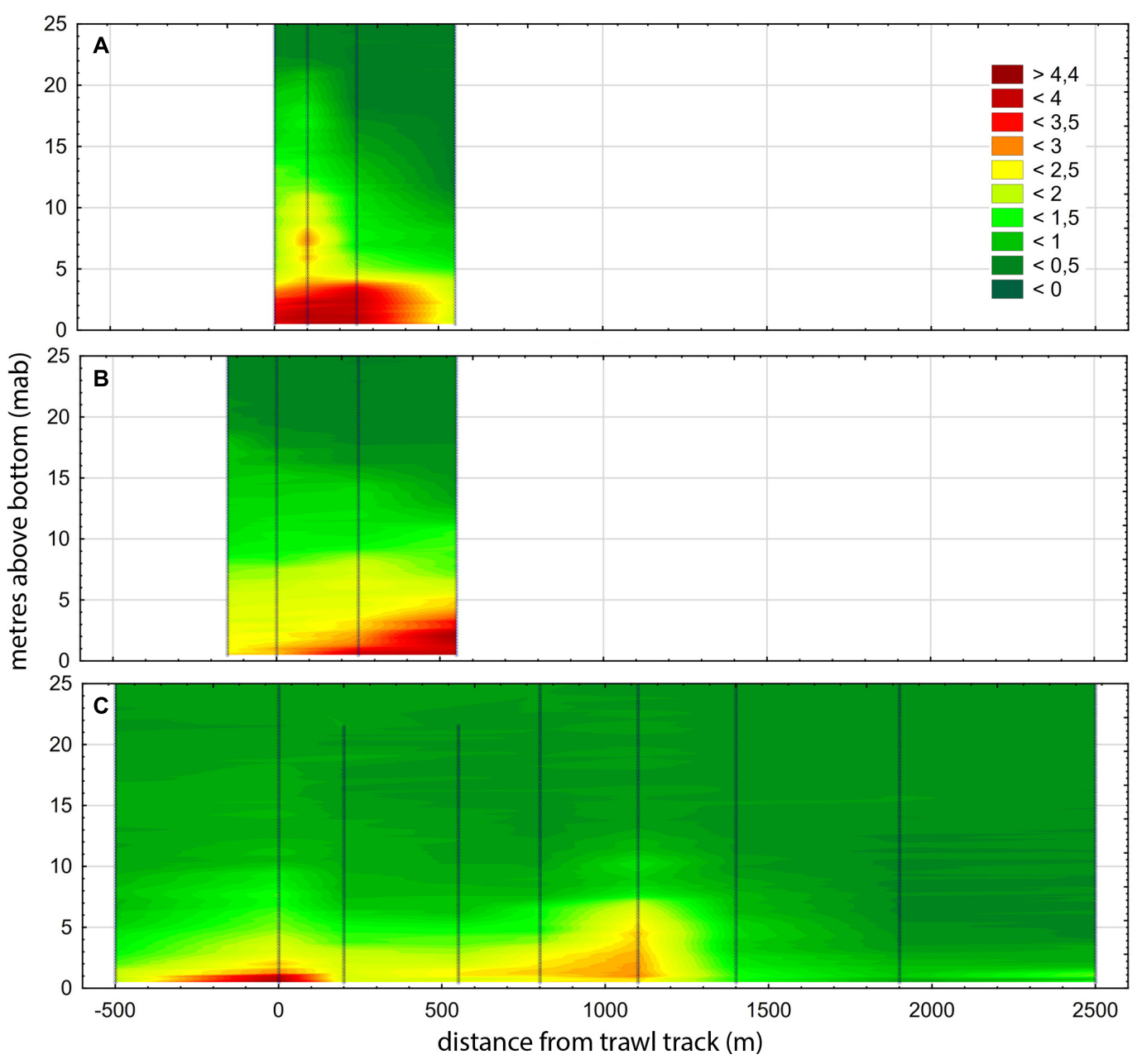

FIGURE 6 | Turbidity (NTU) in the water column at (A) 2 h, (B) 20 h, and (C) 3 days after trawling. The contour plots are based on data (vertical lines of black dots) from a transect of CTD casts across/away from the trawl track ( 0 on the $\mathrm{x}$-axis) in a roughly NW (negative values) to SE (positive values) direction. Wafer plots are based on raw data, i.e., linear interpolation, and no extrapolation beyond the limits of the measured data.

TABLE 2 | Summary of masses of sediment and particulate elements suspended per $\mathrm{m}$ or $\mathrm{m}^{2}$ of trawl track. Sediment masses are $\mathrm{g}$ dry weight.

\begin{tabular}{|c|c|c|c|c|c|c|c|c|}
\hline & Sediment & C & $\mathbf{N}$ & $\mathbf{P}$ & $\mathrm{Fe}$ & Mn & Al & $\mathrm{Ti}$ \\
\hline Suspended ( $\mathrm{g} \mathrm{m}^{-1}$ whole track) & 9,523 & 484 & 57 & 16 & 238 & 12 & 155 & 6 \\
\hline Of which, contribution from trawl doors ( $\mathrm{g} \mathrm{m}^{-1}$ track) & 2,883 & 147 & 17 & 5 & 72 & 4 & 47 & 2 \\
\hline Of which, contribution from groundgear ( $\mathrm{g} \mathrm{m}^{-1}$ track) & 6,640 & 338 & 39 & 11 & 166 & 8 & 108 & 4 \\
\hline Suspended ( $\mathrm{g} \mathrm{m}^{-2}$ whole track) & 263 & 13 & 2 & $<1$ & 7 & $<1$ & 4 & $<1$ \\
\hline Suspended ( $\mathrm{g} \mathrm{m}^{-2}$ door furrow) & 1,030 & 52 & 6 & 2 & 26 & 1.3 & 17 & $<1$ \\
\hline Suspended [ $\mathrm{g} \mathrm{m}^{-2}$ central area (groundgear)] & 199 & 10 & 1.2 & $<1$ & 5 & $<1$ & 3.2 & $<1$ \\
\hline
\end{tabular}

$16 \mathrm{~cm}$ ) deep, to either side of less distinct parallel tracks caused by groundgear, are typical for otter trawl tracks on muddy seabeds (Krost et al., 1990; Tuck et al., 1998; Humborstad et al., 2004; Smith et al., 2007; Palanques et al., 2014). We clearly saw lateral displacement of sediment, particularly on the inside of the door furrow, as described by Gilkinson et al. (1998) and Ivanović et al. (2011). The broken pattern of the door track is also consistent with the "jumping otterboard" tracks described by Krost et al. (1990) and the "herring bone patterns" in Smith et al. (2007).
Many of these studies used side scan sonar and video, the former allowing larger features to be seen over wide areas and the latter providing more detailed images of small-scale features. By using multibeam sonar we were able to combine these two aspects and provide track bathymetry data at a high horizontal and vertical resolution over $>1 \mathrm{~km}$ of track. Only a few other studies have used multibeam sonar for assessing the physical impacts of bottom fishing gear; Malik and Mayer (2007) for scallop dredge tracks on coarse seabeds in the Gulf of Maine, and Depestele 

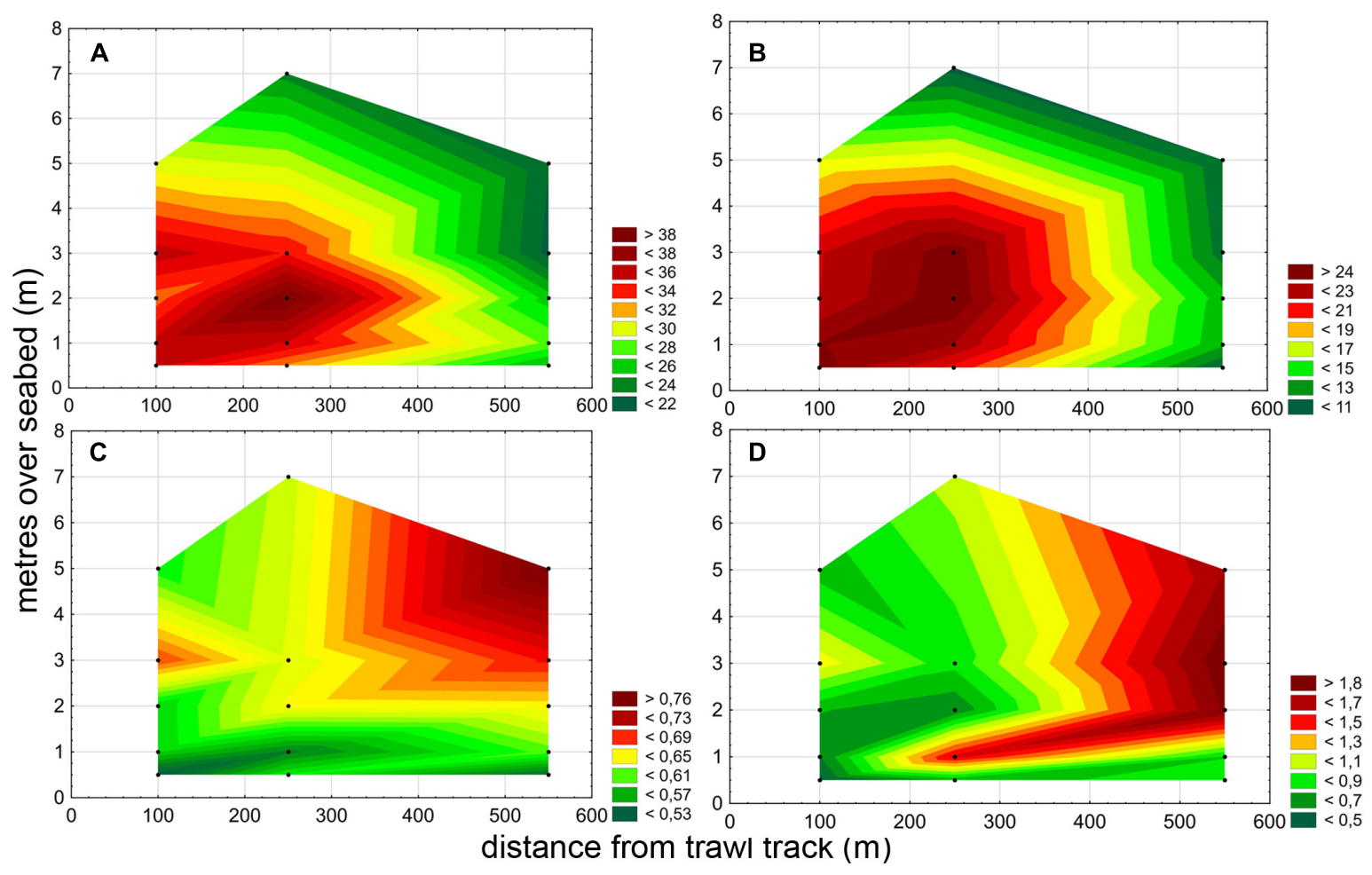

FIGURE 7 | Concentrations of dissolved substances in the bottom water (<7 m.a.b.) at $2 \mathrm{~h}$ after trawling, on a transect up to $550 \mathrm{~m}$ away from the trawl track ("O" on the $x$ axis). Top panel: examples of increased concentrations near the trawl track and near the seabed: (A) total $\mathrm{N}$ (sum of $\left.\mathrm{NH}_{4}-\mathrm{N}, \mathrm{NO}_{2}+\mathrm{NO} \mathrm{O}_{3}-\mathrm{N}\right)$; (B) $\mathrm{Mn}$. Bottom panel: examples of decreased concentrations near the trawl track and near the seabed: (C) Ti; (D) Al. Concentrations are in $\mu \mathrm{g} \mathrm{L}^{-1}$. Vertical lines of black dots show data points on which the wafer plots are based. The plots are based on raw data, i.e., linear interpolation, and no extrapolation beyond the limits of the measured data.

et al. (2016, 2018), Bruns et al. (2020), and Lüdmann et al. (2021) for beam trawls and otter trawls on soft seabeds in the North Sea. These studies have used multibeam data mainly to quantify the number of tracks in a given area and to estimate track dimensions, and sometimes depth penetration. In addition, we also used the multibeam data to quantify the total amount of sediment excavated and displaced; c. $1 \mathrm{~m}^{3}$ or $500 \mathrm{~kg}$ per m of trawl track.

In our study, the trawl track was clearly visible in multibeam bathymetry images 18 months later (Supplementary Figure 4). However, divers were unable to see any clear features, suggesting that the track may have been smoothed out and/or filled in by currents, sedimentation or bioturbation during this time. It appears, however, that the tracks just below the sediment surface are still well-preserved and detected by the multibeam since the acoustic signal penetrates the uppermost centimeters of the seafloor. These trawl-induced changes to surface seabed physical properties have the potential to affect the distribution and survival of benthic organisms that require particular sediment properties (e.g., water or organic carbon content) as well as altering biogeochemical gradients in the sediments. The persistence of the track is in agreement with other authors who have seen that, especially in areas with low background disturbance and on muddy seabeds, tracks may persist from months to years (Krost et al., 1990; Schwinghamer et al., 1998;
Tuck et al., 1998; Smith et al., 2007; Palanques et al., 2014; Oberle et al., 2018; Bunke et al., 2019).

\section{Suspension of Particulate Matter and Extent of the Sediment Plume}

After the single passage of the trawl, a turbid plume (up to $6.9 \mathrm{mgDW} \mathrm{L}^{-1}$ ) was detected in the water column for several days, up to about 10 m.a.b. and $>1 \mathrm{~km}$ downstream from the trawl track. Turbidity values obtained during controlled field experiments vary widely, not only because of differences in gear types and towing speeds (O’Neill and Ivanović, 2016) or type of seabed (O’Neill and Summerbell, 2011; O'Neill and Ivanović, 2016) but also depending on how long after the trawling event, at what distance from the trawl track and height above the seabed the measurements were taken. Studies that have looked at immediate suspension have recorded turbidities of several hundred $\mathrm{mg} \mathrm{L}^{-1}$ close to the gear (e.g., Schoellhamer, 1996; Durrieu de Madron et al., 2005; Dellapenna et al., 2006; Dounas, 2006; Mengual et al., 2016), though these values decrease with time to become comparable to those seen in this study.

When sediment suspension has been calculated as a function of distance or area trawled, values of several hundred g per $\mathrm{m}^{2}$ trawled are commonly reported (Dounas et al., 2005; Durrieu de Madron et al., 2005; Dellapenna et al., 2006; Bradshaw et al., 2012; 


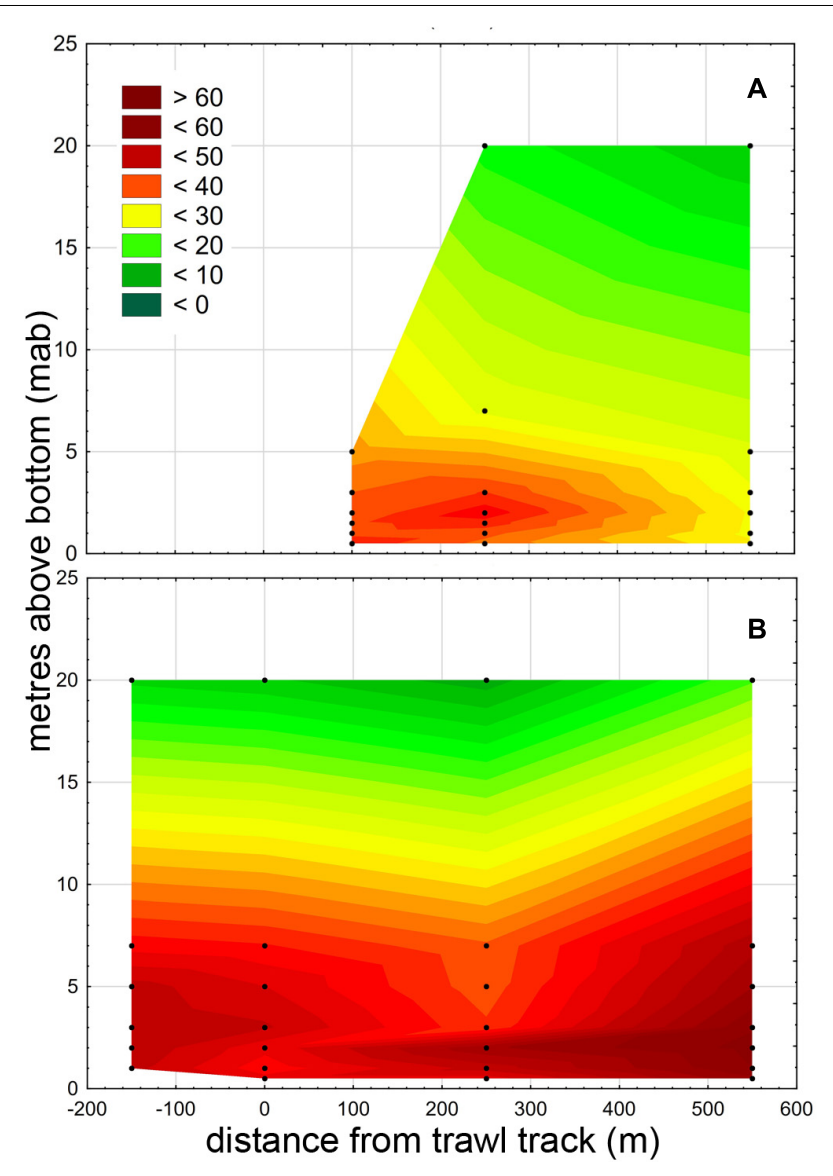

FIGURE 8 | Dissolved $\mathrm{CH}_{4}$ concentrations (nmol L ${ }^{-1}$ ) in the water column along two transects (A) $2 \mathrm{~h}$ and (B) $20 \mathrm{~h}$ after trawling. Contour (wafer) plots are based on data (black dots) from a series of CTD casts across/away from the trawl track (0 on the $\mathrm{x}$-axis) in a roughly NW (negative) to SE (positive) direction. Plots are based on raw data, ie. linear interpolation, and no extrapolation beyond the limits of the measured data.

Mengual et al., 2016), which agrees well with our estimate of $0.25 \mathrm{~kg} \mathrm{~m}^{-2}$ (across the whole track). O'Neill and Summerbell (2011) showed that the trawl doors suspended more sediment per disturbed area (up to nearly $50 \mathrm{~kg} \mathrm{~m}^{-2}$ ) than the groundgear (up to c. $10 \mathrm{~kg} \mathrm{~m}^{-2}$ ). This can be compared to our values of 0.96 and $0.19 \mathrm{~kg} \mathrm{~m}^{-2}$ for the doors and groundgear, respectively. The difference of an order of magnitude between the studies is probably due to our calculations being based on water turbidity $2 \mathrm{~h}$ after trawling, as opposed to seconds after (only 10-15\% of the plume may remain in suspension after $1 \mathrm{~h}$; Durrieu de
Madron et al., 2005). However, the relative difference between the suspension caused by gear parts is the same in both studies (factor of about 5). Since the groundgear has a larger contact area with the sediment than the doors, it can contribute substantially to the total suspension across the whole swept width (Dounas, 2006), something we confirmed in this study (groundgear contributed about $70 \%$ of the total amount suspended).

The initial width of the sediment plume will be the same as the width of the trawl (i.e., distance between trawl doors) but will spread outwards and upwards due to hydrodynamic drag, energy and turbulence generated by the gear and by water currents. Estimates of the initial height of the plume are c. 3-4 m (a few minutes after trawling, Mengual et al., 2016), c. $5.5 \mathrm{~m}$ (30 min after trawling, Durrieu de Madron et al., 2005), 10 m (after c. 30 min, Linders et al., 2017), 15-18 m (after c. 10 min, Bradshaw et al., 2012), all of which are consistent with our results (c. 10$15 \mathrm{~m}$ after $2 \mathrm{~h}$ ). Bradshaw et al. (2012) also identified a separate plume from each trawl door that reached higher into the water column $(15-18 \mathrm{~m})$ than the plume in the central area $(3-4 \mathrm{~m})$ that was probably produced by the groundgear.

Trawl-suspended matter comprises a range of particulate substances such as particulate $\mathrm{C}, \mathrm{N}$ and $\mathrm{P}$ and phaeopigments (e.g., Dounas et al., 2005, 2007; Durrieu de Madron et al., 2005). Our study showed the suspension of both mineral grains (as indicated by particulate $\mathrm{Al}$ and $\mathrm{Ti}$ ) as well as particulate nutrients (particulate $\mathrm{N}$ and $\mathrm{P}$ ) and elements such as $\mathrm{Fe}$ and $\mathrm{Mn}$ in the sediment plume, and the concentrations of these were strongly correlated and changed with time and distance from the trawl track as the sediment plume moved. Oxidation (mineralization) of particulate organic matter can be enhanced if suspended into the water column, particularly if entrained from low oxygen sediment layers into oxygenated water (Blackburn, 1997; Wainright and Hopkinson, 1997; Sciberras et al., 2016); this may partly explain the decrease in $\mathrm{O}_{2}$ in bottom water sometimes observed after trawling (Riemann and Hoffman, 1991), as well as changes in bottom water solutes.

\section{Alterations to Biogeochemistry of Dissolved Substances in the Bottom Water and Sediments}

Our results showed that otter trawling leads to major alterations of bottom water and sediment geochemical parameters. Concentrations of particle-reactive dissolved substances (Al, Fe, and $\mathrm{Ti}$ ) in the bottom water decreased directly after trawling, presumably due to their rapid adsorption to the large amount of suspended matter in the sediment plume. Concentrations of other substances $\left(\mathrm{NH}_{4}, \mathrm{NO}_{\mathrm{x}}, \mathrm{Mn}\right.$ and to a lesser extent

TABLE 3 | Calculated contribution of porewater release to dissolved substances in the bottom water: (A) potential \% of porewater in bottom water above the track, immediately after trawling (with equivalent factor increase compared to pre-trawling concentrations in brackets); (B) potential \% of porewater in bottom $5 \mathrm{~m}$ of water, up to $550 \mathrm{~m}$ from track, after $2 \mathrm{~h}\left(20 \mathrm{~h}\right.$ for $\left.\mathrm{CH}_{4}\right)$.

\begin{tabular}{|c|c|c|c|c|c|c|c|c|c|c|c|}
\hline & Meters above seabed (m.a.b.) & & Al & $\mathrm{Fe}$ & Mn & $\mathrm{Ti}$ & $\mathrm{NH}_{4}$ & $\mathrm{PO}_{4}$ & $\mathbf{N O}_{\mathrm{x}}$ & Tot-N & $\mathrm{CH}_{4}$ \\
\hline \multirow[t]{2}{*}{ (A) } & $0-0.5$ & $\%$ & $77 \%$ & $87 \%$ & $76 \%$ & $22 \%$ & $93 \%$ & $35 \%$ & $17 \%$ & $61 \%$ & $72 \%$ \\
\hline & & (factor) & $(4.4)$ & $(7.7)$ & $(4.1)$ & $(1.3)$ & (13.9) & $(1.5)$ & $(1.2)$ & $(2.6)$ & (3.4) \\
\hline (B) & $0-5$ & & $2.1 \%$ & $4.2 \%$ & $2.1 \%$ & $0.2 \%$ & $4.2 \%$ & $0.4 \%$ & $0.1 \%$ & $0.8 \%$ & $1.2 \%$ \\
\hline
\end{tabular}



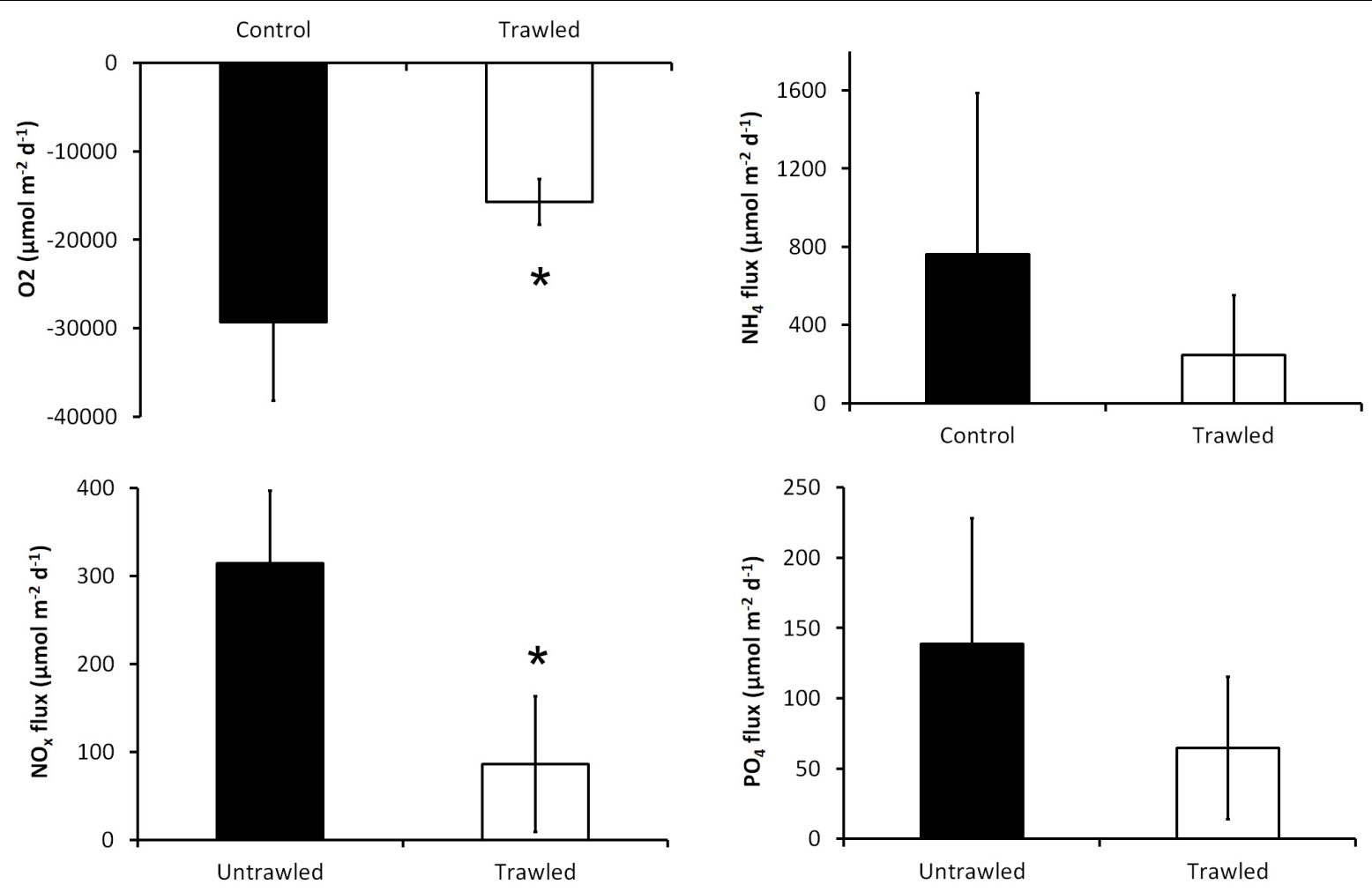

FIGURE 9 | Fluxes of $\mathrm{O}_{2}$ into and nutrients out of the sediment (mean $\left.\pm \mathrm{SE}, n=4\right)$. * Indicates significant difference $(p<0.05)$ between trawled and untrawled sediments. Sediment cores were taken 2 days after trawling.

$\mathrm{PO}_{4}$ ) increased in the bottom water $2 \mathrm{~h}$ after trawling, up to a few hundred meters downstream of the trawl track. Dissolved methane concentrations were around $3 \times$ background $20 \mathrm{~h}$ post-trawling. These changes could be due to: (a) upward mixing of porewater into the water as sediment is suspended (van de Velde et al., 2018) or as pore pressures in the sediment are altered around the moving gear (Gilkinson et al., 1998; Esmaeili and Ivanović, 2014); (b) desorption of substances from suspended particulate matter due to altered redox conditions in the plume (Tiano et al., 2019); (c) increased organic matter mineralization rates in sediments and/or suspended matter (Tiano et al., 2019) or; (d) strengthening or weakening of sediment-water diffusive gradients when sediment is removed from or deposited on the sediment surface (e.g., Warnken et al., 2003). From our calculations, we conclude that a direct release of porewater solutes from the top $2 \mathrm{~cm}$ into the overlying water could produce up to c. $100 \%$ immediate increase in bottom water concentrations. These estimates can be compared with Durrieu de Madron et al. (2005) who calculated that $1-10 \mathrm{~cm}$ sediment was needed to provide the measured concentrations of dissolved substances a few hundred meters behind the trawl. A modeling study by Blackburn (1997) estimated that sedimentary POM from c. 1 to $2.5 \mathrm{~cm}$ sediment must be suspended in order to make any major contribution to $\mathrm{DON}, \mathrm{NH}_{4}$ or $\mathrm{NO}_{3}$ in the overlying water.

Even if only a few $\mathrm{cm}$ (or even $\mathrm{mm}$ ) are disturbed, this layer is where most biological activity occurs; thus, even a shallow impact (e.g., from the groundgear or sweeps) may have a substantial impact on nutrient dynamics (Fanning et al., 1982; Dounas et al., 2005; Morys et al., 2021). We did not detect elevated concentrations of solutes in bottom water $20 \mathrm{~h}$ after trawling, but saw decreased fluxes of nutrients and oxygen in incubated cores taken from the trawl track 2 days after trawling, indicating that the sediments had not fully reequilibrated. This could either be due to depletion of the pool of dissolved nutrients in the surface sediment and/or the slowing of biogeochemical processes due to the removal of the surface sediment, with its labile carbon, porewater solutes and biologically active components. The removal or disruption of the upper sediment layer is supported by sediment profiles of methane, $\mathrm{PO}_{4}, \mathrm{NH}_{4}$ and $\mathrm{NO}_{\mathrm{x}}$, which were all elevated in the top $5 \mathrm{~cm}$ compared to sediment profiles $100 \mathrm{~m}$ from the track (Supplementary Figure 6). In the undisturbed cores, these compounds only occur at high concentrations in the deeper parts of the sediment core. The high concentrations are due to the diagenetic release during anaerobic organic matter remineralization by manganese, iron, sulfate reduction and methanogenesis in the deeper anoxic parts of the sediment and their higher concentrations in the trawl track porewaters suggest physical mixing by the trawl or removal of the topmost sediment layer. Concentration profiles of chlorophyll, organic matter and porosity (Supplementary Figure 5) also confirm the removal or displacement of the surface sediment, and thus an apparent upward shift of these profiles compared to undisturbed sediment, in agreement with Morys et al. (2021) in a similar study in the area. 


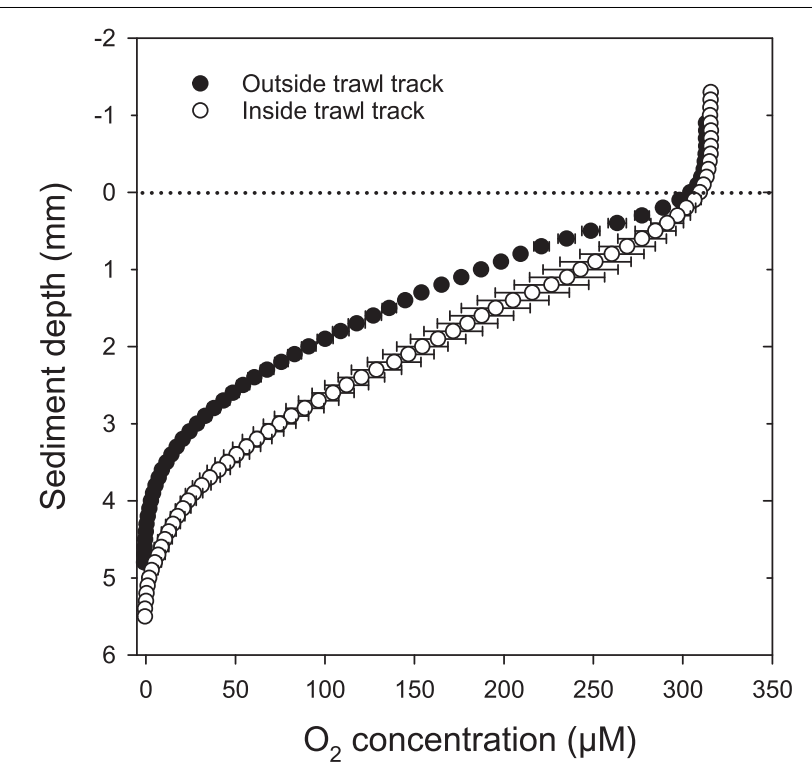

FIGURE 10 | Porewater oxygen microprofiles in sediment cores taken 2 days after trawling. Circles represent average values of three profiles taken from the same core and error bars are standard errors.

Changes in benthic $\mathrm{O}_{2}$ microprofiles suggested that 2 days after trawling the impacted sediment was less reactive (greater oxygen penetration depth, OPD) than the control sediment. Similar trends in OPD were observed by Tiano et al. (2019) and in groundgear tracks by Dellapenna et al. (2006). However, the opposite trend was seen by Warnken et al. (2003), Dellapenna et al. (2006), and Ferguson et al. (2020) in trawl door tracks, the latter study emphasizing the variability in response in different parts of the track due to the different nature of the physical disturbance by different parts of the gear.

Changes in dissolved element fluxes due to physical disturbance are usually short-lived pulses (hours) that disappear as sediment and water chemistry re-equilibrate (Riemann and Hoffman, 1991; Blackburn, 1997; Duplisea et al., 2001; Dounas et al., 2005, 2007; Durrieu de Madron et al., 2005; Percival et al., 2005; Dounas, 2006), as we also observed in this study. Thus, the exact time at which measurements are made relative to the time of disturbance is critical, and effects may vary temporally and spatially within a single study (e.g., Riemann and Hoffman, 1991; Zacharia et al., 2006; Ferguson et al., 2020). Effects also depend on how well-oxygenated the sediments are and if disturbance disrupts the oxic/anoxic boundary (Duplisea et al., 2001; Trimmer et al., 2005; Ferguson et al., 2020). In the Baltic Sea, this boundary is commonly less than $2 \mathrm{~cm}$ deep in oxygenated waters (Bonaglia et al., 2013; Almroth-Rosell et al., 2015), so the potential for disruption by trawling is high.

\section{Implications of Trawling-Induced Sediment Disturbance and Suspension}

Short term suspension effects will likely cause a transient impact on biogeochemical processes in the bottom water in the immediate vicinity of the trawl tracks, but more important is the spatial and temporal persistence of the sediment plume in relation to background turbidity. Field studies that have measured these aspects are difficult to compare as local sediment type and hydrographical conditions determine the spread and fate of suspended matter. However, Bradshaw et al. (2012) and Linders et al. (2017) showed that a plume of fine sediment was still clearly detectable several days after trawling, just as we found in this study. Those authors, as well as Schubel et al. (1979), Churchill (1989), Schoellhamer (1996), Palanques et al. (2001, 2014), and Mengual et al. (2016) concluded that trawling likely contributed substantially to overall suspension and turbidity in the bottom water in the frequently trawled areas where those studies were performed. The relative contribution can also be higher during seasons where fishing is most intensive and natural suspension and sedimentation processes are low (Churchill, 1989; Palanques et al., 2014; Mengual et al., 2016). When suspended sediment is transported away from trawled areas, it can cause large-scale export of sediment to other areas, for example off-shelf (Churchill, 1989; Palanques et al., 2001; Ferré et al., 2008; Oberle et al., 2016b, 2018; Paradis et al., 2018), thus potentially affecting areas that are not themselves trawled.

While some authors have argued that physical disturbance simply speeds up a release of sediment solutes that would anyway have occurred more slowly through diffusion or bioturbation (Sloth et al., 1996; Blackburn, 1997), others argue that alterations to sediment stability and structure, sediment redox conditions, and benthic communities (especially bioturbators) may lead to chronic longer-term changes in sediment biogeochemistry (e.g., Duplisea et al., 2001) and sediment-water fluxes. The frequency of disturbance is probably important; disturbance at a frequency greater than the timescale needed for reequilibration of sediment biogeochemical gradients may result in these sediments always being in a transient state (Duplisea et al., 2001; van de Velde et al., 2018). Lastly, trawling may even have wider-reaching local or regional impacts. Dissolved effluxes from trawling have been estimated, for example, to contribute to annual $\mathrm{N}$ and Si budgets (Gulf of Maine; Pilskaln et al., 1998) or productivity (Gulf of Heraklion; Dounas et al., 2007), or to have chronically affected nutrient dynamics [North Sea; Percival et al., 2005 (in contrast to findings by Trimmer et al., 2005)]. Suspension of organic-rich particles is also known to increase organic matter remineralization and oxygen consumption (Riemann and Hoffman, 1991; van de Velde et al., 2018), with implications for the sediments' carbon storage capacity (Legge et al., 2020; Sala et al., 2021). In the Baltic Sea, where commercial bottom trawling frequently occurs close to areas of low oxygen bottom water (van Denderen et al., 2020), further decreases in oxygen caused by trawling also have the potential to exacerbate existing conditions of oxygen stress.

\section{Conclusion and Perspectives}

A single trawling event with an otter trawl on a muddy seafloor created a distinct trawl track that was still detectable 18 months later. The trawling event displaced c. $500 \mathrm{t}$ sediment per $\mathrm{km}$ of track, decreasing oxygen penetration depth and nutrient and 
oxygen fluxes across the sediment-water interface in the track for at least $48 \mathrm{~h}$. Approximately $9.5 \mathrm{t}$ sediment, including tens to hundreds of $\mathrm{kg}$ of associated particulate elements such as $\mathrm{Al}$, $\mathrm{Fe}, \mathrm{P}$, and $\mathrm{Mn}$, were suspended per $\mathrm{km}$ of track; the sediment plume in the near-bottom water was transported more than $1 \mathrm{~km}$ away over the following 3-4 days. A short term release (hours) of dissolved substances (e.g., N, P, Mn, methane) was also observed in the vicinity of the track, however dissolved concentrations of particle-reactive elements (e.g., Al, Fe, Ti) near the seafloor decreased immediately after trawling; we suggest that this is due to them rapidly adsorbing to the suspended particles in the sediment cloud.

In order to more fully clarify the mechanisms of the biogeochemical processes occurring in the days after trawling, we suggest future experimental field studies take more detailed measurements of the suspended particulate and dissolved phases that were not possible in the scope of this study. Fine resolution measurements of the suspended particulate matter, dissolved oxygen, $\mathrm{pH}$, alkalinity and dissolved organic and inorganic carbon in the bottom water over space and time would contribute to a better understanding of organic matter mineralization and speciation of suspended elements. In addition, sediment profiling of oxygen and dissolved and particulate substances in different areas of the track (e.g., door furrows and adjacent sediment piles, groundgear tracks) and over a number days or weeks would improve the mechanistic understanding of effects on biogeochemical processes and their recovery from a trawling event.

Although this study focused on the short term effects of a single passage of a small trawl, it highlights the potential for larger and longer-term effects in areas where disturbance by commercial trawling is frequent. Not only may seabed biogeochemical processes not have sufficient time to re-equilibrate between trawling events, but trawl-induced turbidity in the bottom water may be semi-permanent in areas with high trawling intensity and affect local, or even regional, nutrient and element cycling. According to the Marine Strategy Framework Directive (EU, 2008), "seafloor integrity" (i.e., physical, chemical and biological characteristics, ecosystem processes, and spatial connectivity; Rice et al., 2012) shall be safeguarded in order to ensure "good environmental status," i.e., a state where "the structure and functions of the ecosystems are safeguarded and benthic ecosystems, in particular, are not adversely affected" (EU, 2017). In addition, hydrographical conditions should not be altered in a way that adversely affect marine ecosystems. It is clear from our study that bottom trawling has the potential to affect physical, chemical and biological aspects of seafloor integrity, as well as water quality (i.e., hydrographical conditions) both within and outside trawled areas.

\section{REFERENCES}

Almroth-Rosell, E., Eilola, K., Kuznetsov, I., Hall, P. O. J., and Meier, H. E. M. (2015). A new approach to model oxygen dependent benthic phosphate fluxes in the Baltic Sea. J. Mar. Syst. 144, 127-141. doi: 10.1016/j.jmarsys.2014.11.007

\section{DATA AVAILABILITY STATEMENT}

The raw data supporting the conclusions of this article will be made available by the authors on request, without undue reservation.

\section{AUTHOR CONTRIBUTIONS}

$\mathrm{CB}$ coordinated the project, did most of the data analyses and calculations, and wrote the majority of the article. CB, MJ, and MS designed and carried out the fieldwork. MJ carried out the acoustic measurements and all associated data analysis and wrote those parts of the article. SB, VB, and C-MM carried out biogeochemical analyses and contributed to the associated data analyses. JM and CS processed and interpreted the ADCP data. All authors contributed to the data interpretation and manuscript revision.

\section{FUNDING}

This work was financed by a grant from the Swedish Research Council for Environment, Agricultural Sciences and Spatial Planning (Formas), Grant No. 2017-00866 (Principle Investigator; $\mathrm{CB}$ ). Open Access publication fees were paid for by Stockholm University.

\section{ACKNOWLEDGMENTS}

We thank the crew of R/V Electra af Askö and staff at the Stockholm University's Askö Marine Laboratory; Kjell-Åke Karlsson, captain of the fishing vessel Ellis; Björn Eriksson, IGV (SU), for technical support in the field; the Marine Ecology Lab, DEEP (SU), Nellie Stjärnkvist, Henrik Sandberg, Maysoon Lundevall Zara, and Thea Bisander for sample analysis; Jim Hansson and his dive team, Archaeology Unit, Swedish National Maritime and Transport Museums; and Claudia Morys for valuable comments on the manuscript. The County Administrative Board (Södermanland) granted permission to perform this experiment in the Askö nature reserve. The multibeam bathymetry and sub-bottom profiles presented in this work have been granted public release by the Swedish Maritime Administration (Ref. No. 15-01844).

\section{SUPPLEMENTARY MATERIAL}

The Supplementary Material for this article can be found online at: https://www.frontiersin.org/articles/10.3389/fmars. 2021.683331/full\#supplementary-material

Amoroso, R. O., Pitcher, C. R., Rijnsdorp, A. D., McConnaughey, R. A., Parma, A. M., Suuronen, P., et al. (2018). Bottom trawl fishing footprints on the world's continental shelves. Proc. Natl. Acad. Sci. U.S.A. 115, E10275-E10282.

Bange, H. W., Bergmann, K., Hansen, H. P., Kock, A., Koppe, R., Malien, F., et al. (2010). Dissolved methane during hypoxic events at the Boknis Eck time 
series station (Eckernförde Bay, SW Baltic Sea). Biogeosciences 7, 1279-1284. doi: 10.5194/bg-7-1279-2010

Black, K. P., and Parry G. D. (1994). Sediment transport rates and sediment disturbance due to scallop dredging in Port Phillip Bay. Mem. Queensl. Mus. $36,327-341$

Blackburn, T. H. (1997). Release of nitrogen compounds following resuspension of sediment: model predictions. J. Mar. Syst. 11, 343-352. doi: 10.1016/s09247963(96)00129-7

Bonaglia, S., Bartoli, M., Gunnarsson, J. S., Rahm, L., Raymond, C., Svensson, O., et al. (2013). Effect of reoxygenation and Marenzelleria spp. bioturbation on Baltic Sea sediment metabolism. Mar. Ecol. Prog. Ser. 482, 43-55. doi: $10.3354 /$ meps 10232

Bower, C. E., and Holm-Hansen, T. (1980). A salicylate-hypochlorite method for determining ammonia in seawater. Can. J. Fish. Aquat. Sci. 37, 794-798. doi: 10.1139/f80-106

Bradshaw, C., Tjensvoll, I., Sköld, M., Allan, I., Molvaer, J., Magnusson, J., et al. (2012). Bottom trawling resuspends sediment and releases bioavailable contaminants in a polluted fjord. Environ. Pollut. 170, 232-241. doi: 10.1016/j. envpol.2012.06.019

Bradshaw, C., Veale, L. O., and Brand, A. R. (2002). The role of scallop-dredge disturbance in long-term changes in Irish Sea benthic communities: a reanalysis of an historical dataset. J. Sea Res. 47, 161-184. doi: 10.1016/s13851101(02)00096-5

Brown, E. J., Finney, B., Dommisse, M., and Hills, S. (2005). Effects of commercial otter trawling on the physical environment of the southeastern Bering Sea. Cont. Shelf Res. 25, 1281-1301. doi: 10.1016/j.csr.2004.12.005

Bruns, I., Holler, P., Capperucci, R. M., Papenmeier, S., and Bartholomä, A. (2020). Identifying trawl marks in north sea sediments. Geosciences 10:422. doi: 10. 3390/geosciences 10110422

Bunke, D., Leipe, T., Moros, M., Morys, C., Tauber, F., Virtasalo, J. J., et al. (2019). Natural and anthropogenic sediment mixing processes in the south-western baltic sea. Front. Mar. Sci. 6:677. doi: 10.3389/fmars.2019.00677

Churchill, J. H. (1989). The effect of commercial trawling on sediment resuspension and transport over the Middle Atlantic Bight continental shelf. Cont. Shelf Res. 9, 841-865. doi: 10.1016/0278-4343(89)90016-2

Dellapenna, T. M., Allison, M. A., Gill, G. A., Lehman, R. D., and Warnken, K. W. (2006). The impact of shrimp trawling and associated sediment resuspension in mud dominated, shallow estuaries. Estuarine Coast. Shelf Sci. 69, 519-530. doi: 10.1016/j.ecss.2006.04.024

Depestele, J., Degrendele, K., Esmaeili, M., Ivanović, A., Kröger, S., O’Neill, F. G., et al. (2018). Comparison of mechanical disturbance in soft sediments due to tickler-chain SumWing trawl vs. electro-fitted PulseWing trawl. ICES J. Mar. Sci. 76, 312-329. doi: 10.1093/icesjms/fsy124

Depestele, J., Ivanović, A., Degrendele, K., Esmaeili, M., Polet, H., Roche, M., et al. (2016). Measuring and assessing the physical impact of beam trawling. ICES J. Mar. Sci. 73, i15-i26.

Dounas, C., Davies, I., Triantafyllou, G., Koulouri, P., Petihakis, G., Arvanitidis, C., et al. (2007). Large-scale impacts of bottom trawling on shelf primary productivity. Cont. Shelf Res. 27, 2198-2210. doi: 10.1016/j.csr.2007. 05.006

Dounas, C. G. (2006). A new apparatus for the direct measurement of the effects of otter trawling on benthic nutrient releases. J. Exp. Mar. Bio Ecol. 339, 251-259. doi: $10.1016 /$ j.jembe.2006.07.022

Dounas, C. G., Davies, I. M., Hayes, P. J., Arvanitidis, C. D., and Koulouri, P. T. (2005). The effects of different types of otter trawl ground rope on benthic nutrient releases and sediment biogeochemistry. Am. Fisheries Soc. Symposium $41,539-544$.

Duplisea, D. E., Jennings, S., and Malcolm, S. J. (2001). Modelling potential impacts of bottom trawl fisheries on soft sediment biogeochemistry in the North Sea. Geochem. Trans. 2:112.

Durrieu de Madron, X., Ferré, B., and Le Corre, G. (2005). Trawling-induced resuspension and dispersal of muddy sediments and dissolved elements in the Gulf of Lion (NW Mediterranean). Cont. Shelf Res. 25, 2387-2409. doi: 10.1016/j.csr.2005.08.002

Eigaard, O. R., Bastardie, F., Breen, M., Dinesen, G. E., Hintzen, N. T., Laffargue, P., et al. (2016). Estimating seabed pressure from demersal trawls, seines, and dredges based on gear design and dimensions. ICES J. Mar. Sci. 73 (Suppl. 1), i27-i43. doi10.1093/icesjms/fsv099
Eigaard, O. R., Bastardie, F., Hintzen, N. T., Buhl-Mortensen, L., Buhl-Mortensen, P., Catarino, R., et al. (2017). The footprint of bottom trawling in European waters: distribution, intensity, and seabed integrity. ICES J. Mar. Sci. 74, 847-865. doi: 10.1093/icesjms/fsw194

Esmaeili, M., and Ivanović, A. (2014). Numerical modeling of fishing ground gear component on the seabed. Ocean Eng. 91, 316-328. doi: 10.1016/j.oceaneng. 2014.08.014

EU (2008). Directive 2008/56/EC of the European Parliament and of the Council of 17 June 2008, establishing a framework for community action in the field of marine environmental policy (Marine Strategy Framework Directive). Off. J. Eur. Union L 164, 19-40.

EU (2017). Commission Decision (EU) 2017/848 of 17 May 2017 laying down criteria and methodological standards on good environmental status of marine waters and specifications and standardised methods for monitoring and assessment, and repealing Decision 2010/477/EU. Off. J. Eur. Union L $125 / 43$.

Fanning, K. A., Carder, K. L., and Betzer, P. R. (1982). Sediment resuspension by coastal waters: a potential mechanism for nutrient re-cycling on the ocean's margins. Deep Sea Res. Part A Oceanogr. Res. Pap. 29, 953-965. doi: 10.1016/ 0198-0149(82)90020-6

Ferguson, A. J. P., Oakes, J., and Eyre, B. D. (2020). Bottom trawling reduces benthic denitrification and has the potential to influence the global nitrogen cycle. Limnol. Oceanogr. 5, 237-245. doi: 10.1002/lol2.10150

Ferré, B., Durrieu de Madron, X., and Estournel, C. (2008). Impact of natural (waves and currents) and anthropogenic (trawl) resuspension on the export of particulate matter to the open ocean. Application to the Gulf of Lion (NW Mediterranean). Cont. Shelf Res. 28, 2071-2091. doi: 10.1016/j.csr.2008. 02.002

Gilkinson, K., Paulin, M., Hurley, S., and Schwinghamer, P. (1998). Impacts of trawl door scouring on infaunal bivalves: results of a physical trawl door model/dense sand interaction. J. Exp. Mar. Biol. Ecol. 224, 291-312. doi: 10.1016/s00220981(97)00207-4

HELCOM (1988). "Guidelines for the Baltic Monitoring Programme for the third stage. Part A. Introductory chapters," in Proceeding of the Baltic Sea Environment Proceedings No. 27A (Helsinki: Baltic Marine Environment Protection Commission).

HELCOM (2018). "State of the baltic sea - second HELCOM holistic assessment 2011-2016," in Proceeding of the Baltic Sea Environment Proceedings 155 (HELCOM), 155.

Hiddink, J. G., Jennings, S., Sciberras, M., Szostek, C. L., Hughes, K. M., Ellis, N., et al. (2017). Global analysis of depletion and recovery of seabed biota after bottom trawling disturbance. Proc. Natl. Acad. Sci. U.S.A. 114, 8301-8306. doi: $10.1073 /$ pnas. 1618858114

Humborstad, O. B., Nøttestad, L., Løkkeborg, S., and Rapp, H. T. (2004). RoxAnn bottom classification system, sidescan sonar and video-sledge: spatial resolution and their use in assessing trawling impacts. ICES J. Mar. Sci. 61, 53-63. doi: 10.1016/j.icesjms.2003.10.001

ICES (2018). Baltic Sea Ecoregion - Fisheries Overview. ICES Fisheries Overviews. Baltic Sea Ecoregion. 30 Nov 2018. Available online at: https://doi.org/10.17895/ ices.pub.4648.

ICES (2020a). Baltic Sea Ecoregion - Ecosystem overview. In Report of the ICES Advisory Committee, 2020. ICES Advice 2020, Section 4.1. Available online at: https://doi.org/10.17895/ices.advice.7635.

ICES (2020b). Cod (Gadus morhua) in Subdivisions 22-24, Western Baltic Stock (Western Baltic Sea). ICES Advice on Fishing Opportunities, Catch, and Effort. Baltic Sea Ecoregion, 29 May 2020. ICES Advice 2020 - cod.27.22-24. Available online at: https://doi.org/10.17895/ices.advice.5942.

ICES (2020c). Cod (Gadus morhua) in Subdivisions 24-32, Eastern Baltic Stock (Eastern Baltic Sea). ICES Advice on Fishing Opportunities, Catch, and Effort. Baltic Sea Ecoregion, 29 May 2020, version 2: 3 June 2020. ICES Advice $2020-$ cod.27.24-32. Available online at: https://doi.org/10.17895/ices.advice.5943.

Ivanović, A., Neilson, R. D., and O’Neill, F. G. (2011). Modelling the physical impact of trawl components on the seabed. Ocean Eng. 38, 925-933. doi: 10.1016/j.oceaneng.2010.09.011

Jakobsson, M., O’Regan, M., Mörth, C.-M., Stranne, C., Weidner, E., Hansson, J., et al. (2020). Potential links between Baltic Sea submarine terraces and groundwater seeping. Earth Surface Dynamics 8, 1-15. doi: 10.5194/esurf-8$1-2020$ 
Jennings, S., and Kaiser, M. J. (1998). The effects of fishing on marine ecosystems. Adv. Mar. Biol. 34, 201-352. doi: 10.1016/s0065-2881(08)60212-6

Kaiser, M. J., Clarke, K. R., Hinz, H., Austen, M. C. V., Somerfield, P. J., and Karakassis, I. (2006). Global analysis of response and recovery of benthic biota to fishing. Mar. Ecol. Progr. Series 311, 1-1. doi: 10.3354/meps311001

Kaiser, M. J., Collie, J. S., Hall, S. J., Jennings, S., and Poiner, I. R. (2002). Modification of marine habitats by trawling activities: prognosis and solutions. Fish Fish 3, 114-136. doi: 10.1046/j.1467-2979.2002.00079.x

Koroleff, F. (1983). "Determination of phosphorus," in Methods of Seawater Analysis, eds K. Grasshoff, M. Ehrhardt, and K. Kremling (Weinheim: Verlag Chemie), 125-139.

Krost, P. (1990). Der Einfluß der grundschleppnetzfischerei auf nährsalzfreisetzung aus dem sediment und makrofauna der kieler bucht (Westl. Ostsee). Berichte aus dem Inst. für Meereskd. 200:167.

Krost, P., Bernhard, M., Werner, F., and Hukriede, W. (1990). Otter trawl tracks in Kiel Bay (Western Baltic) mapped by side-scan sonar. Meeresforschung 32, 344-353.

Legge, O., Johnson, M., Hicks, N., Jickells, T., Diesing, M., Aldridge, J., et al. (2020). Carbon on the Northwest European Shelf: contemporary budget and future influences. Front. Mar. Sci. 7:143. doi: 10.3389/fmars.2020.00143

Linders, T., Nilsson, P., Wikström, A., and Mattias Sköld, M. (2017). Distribution and fate of trawling-induced suspension of sediments in a marine protected area. ICES J. Mar. Sci. 75, 785-795. doi: 10.1093/icesjms/fsx 196

Lüdmann, T., Saitz, Y. M., Metzing, J., and Emeis, K.-C. (2021). Acoustic backscatter analysis of ground-fishing activity in the German North Sea sector. Cont. Shelf Res. 212:104292. doi: 10.1016/j.csr.2020.104292

Magris, R. A., and Ban, N. C. (2019). A meta-analysis reveals global patterns of sediment effects on marine biodiversity. Glob. Ecol. Biogeogr. 28, 1879-1898. doi: $10.1111 /$ geb.12990

Malik, M., and Mayer, L. (2007). Investigation of seabed fishing impacts on benthic structure using multi-beam sonar, sidescan sonar, and video. ICES J. Mar. Sci. 1998, 1053-1065. doi: 10.1093/icesjms/fsm056

Martín, J., Puig, P., Palanques, A., and Giamportone, A. (2014). Commercial bottom trawling as a driver of sediment dynamics and deep seascape evolution in the Anthropocene. Anthropocene 7, 1-15. doi: 10.1016/j.ancene.2015.01.002

Mengual, B., Cayocca, F., and Le Hir, P. (2016). Influence of bottom trawling on sediment resuspension in the "Grande-Vasière" area (Bay of Biscay, France). Ocean Dyn 66, 1181-1207. doi: 10.1007/s10236-016-0974-7

Morys, C., Brüchert, V., and Bradshaw, C. (2021). Impacts of bottom trawling on benthic biogeochemistry in muddy sediments: removal of surface sediment using an experimental field study. Mar. Environ. Res. 169:105384. doi: 10.1016/ j.marenvres.2021.105384

Oberle, F. K. J., Puig, P., and Martín, J. (2018). "Fishing Activities," in Submarine Geomorphology, eds A. Micallef, S. Krastel, and A. Savini (Berlin: Springer Geology).

Oberle, F. K. J., Storlazzi, C. D., and Hanebuth, T. J. J. (2016a). What a drag: quantifying the global impact of chronic bottom trawling on continental shelf sediment. J. Mar. Syst. 159, 109-119. doi: 10.1016/j.jmarsys.2015.12.007

Oberle, F. K. J., Swarzenski, P. W., and Reddy, C. M. (2016b). Deciphering the lithological consequences of bottom trawling to sedimentary habitats on the shelf. J. Mar. Syst. 159, 120-131. doi: 10.1016/j.jmarsys.2015.12.008

Olsgard, F., Schaanning, M. T., and Widdicombe, S. (2008). Effects of bottom trawling on ecosystem functioning. J. Exp. Mar. Bio. Ecol. 366, 123-133. doi: 10.1016/j.jembe.2008.07.036

O'Neill, F., and Summerbell, K. (2011). The mobilisation of sediment by demersal otter trawls. Mar. Pollut. Bull. 62, 1088-1097. doi: 10.1016/j.marpolbul.2011. 01.038

O’Neill, F. G., and Ivanović, A. (2016). The physical impact of towed demersal fishing gears on soft sediments. ICES J. Mar. Sci. 73, i5-i14.

O’Neill, F. G., Robertson, M., Summerbell, K., Breen, M., and Robinson, L. A. (2013a). The mobilisation of sediment and benthic infauna by scallop dredges. Mar. Environ. Res. 90, 104-112. doi: 10.1016/j.marenvres.2013. 06.003

O’Neill, F. G., Simmons, S. M., Parsons, D. R., Best, J. L., Copland, P. J., Armstrong, F., et al. (2013b). Monitoring the generation and evolution of the sediment plume behind towed fishing gears using a multibeam echosounder. ICES J. Mar. Sci. 70, 892-903. doi: 10.1093/icesjms/fst051
Palanques, A., Guillén, J., and Puig, P. (2001). Impact of bottom trawling on water turbidity and muddy sediment of an unfished continental shelf. Limnol. Oceanogr. 46, 1100-1110. doi: 10.4319/lo.2001.46.5.1100

Palanques, A., Puig, P., and Guillén, J. (2014). Effects of bottom trawling on the Ebro continental shelf sedimentary system (NW Mediterranean). Cont. Shelf Res. 72, 83-98. doi: 10.1016/j.csr.2013.10.008

Paradis, S., Puig, P., Masqué, P., Juan-Díaz, X., Martín, J., and Palanques, A. (2017). Bottom-trawling along submarine canyons impacts deep sedimentary regimes. Nat. Sci. Rep. 7:43332.

Paradis, S., Puig, P., Sanchez-Vidal, A., Masqué, P., Garcia-Orellana, J., Calafat, A., et al. (2018). Spatial distribution of sedimentation-rate increases in Blanes Canyon caused by technification of bottom trawling fleet. Progr. Oceanogr. 169, 241-252. doi: 10.1016/j.pocean.2018.07.001

Percival, P., Frid, C., and Upstill-Goddard, R. (2005). The impact of trawling on benthic nutrient dynamics in the North Sea: implications of laboratory experiments. Am. Fisheries Soc. Sympos. 41, 491-501.

Pilskaln, C., Churchill, J., and Mayer, L. (1998). Resuspension of sediment by bottom trawling in the Gulf of Maine and potential geochemical consequences. Conserv. Biol. 12, 1223-1229. doi: 10.1046/j.1523-1739.1998.0120061223.x

Puig, P., Martín, J., Masqué, P., and Palanques, A. (2015). Increasing sediment accumulation rates in La Fonera (Palamós) submarine canyon axis and their relationship with bottom trawling activities. Geophys. Res. Lett. 42, 8106-8113. doi: $10.1002 / 2015 \mathrm{gl} 065052$

Pusceddu, A., Fiordelmondo, C., Polymenakou, P., Polychronaki, P., Tselepides, A., and Danovaro, R. (2005). Effects of bottom trawling on the quantity and biochemical composition of organic matter in coastal marine sediments (Thermaikos Gulf, northwestern Aegean Sea). Cont. Shelf Res. 25, 2491-2505. doi: 10.1016/j.csr.2005.08.013

Rice, J., Arvanitidis, C., Borja, A., Frid, C., Hiddink, J. G., Krause, J., et al. (2012). Indicators for sea-floor integrity under the european marine strategy framework directive. Ecol. Indicators 12, 174-184. doi: 10.1016/j.ecolind.2011. 03.021

Riemann, B., and Hoffman, E. (1991). Ecological consequences of dredging and bottom trawling in the Limfjord, Denmark. Mar. Ecol. Prog. Ser. 69, 171-178. doi: 10.3354/meps069171

Rijnsdorp, A. D., Bolam, S. G., Garcia, C., Hiddink, J. G., Hintzen, N. T., van Denderen, P. D., et al. (2018). Estimating sensitivity of seabed habitats to disturbance by bottom trawling based on the longevity of benthic fauna. Ecol. Appl. 28, 1302-1312. doi: 10.1002/eap.1731

Sala, E., Mayorga, J., Bradley, D., Cabral, R. B., Atwood, T. B., Auber, A., et al. (2021). Protecting the global ocean for biodiversity, food and climate. Nature 592, 397-402. doi: 10.1038/s41586-021-03371-z

Sawicka, J. E., and Brüchert, V. (2017). Annual variability and regulation of methane and sulfate fluxes in Baltic Sea estuarine sediments. Biogeosciences 14, 325-339. doi: 10.5194/bg-14-325-2017

Schnetger, B., and Lehners, C. (2014). Determination of nitrate plus nitrite in small volume marine water samples using vanadium(III)chloride as a reduction agent. Mar. Chem. 160, 91-98. doi: 10.1016/j.marchem.2014.01.010

Schoellhamer, D. H. (1996). Anthropogenic sediment resuspension mechanisms in a shallow microtidal estuary. Estuarine Coast. Shelf Sci. 43, 533-548. doi: 10.1006/ecss. 1996.0086

Schubel, J. R., Carter, H. H., and Wise, W. M. (1979). Shrimping as a source of suspended sediment in Corpus Christi Bay (Texas). Estuaries 2, 201-203. doi: $10.2307 / 1351737$

Schwinghamer, P., Gordon, D. C., and Rowell, T. W. (1998). Effects of experimental otter trawling on surficial sediment properties of a sandy-bottom ecosystem on the Grand Banks of Newfoundland. Conserv. Biol. 12, 1215-1222. doi: 10.1046/j.1523-1739.1998.0120061215.x

Sciberras, M., Parker, R., Powell, C., Robertson, C., Kröger, S., Bolam, S., et al. (2016). Impacts of bottom fishing on the sediment infaunal community and biogeochemistry of cohesive and non-cohesive sediments. Limnol. Oceanogr. 61, 2076-2089. doi: 10.1002/lno.10354

Seeberg-Elverfeldt, J., Schlüter, M., Feseker, T., and Kölling, M. (2005). Rhizon sampling of porewaters near the sediment-water interfaceof aquatic systems. Limnol. Oceanogr.: Methods 3, 361-371. doi: 10.4319/lom.2005.3.361

Sloth, N. P., Riemann, B., Nielsen, L. P., and Blackburn, T. H. (1996). Resilience of pelagic and benthic communities to sediment resuspension in a coastal 
ecosystem, Knebel Vig, Denmark. Estuarine Coast. Shelf Sci. 42, 405-415. doi: 10.1006/ecss.1996.0027

Smith, C. J., Banks, A. C., and Papadopoulou, K.-N. (2007). Improving the quantitative estimation of trawling impacts from sidescan-sonar and underwater-video imagery. ICES J. Mar. Sci. 64, 1692-1701. doi: 10.1093/ icesjms/fsm 165

Smith, C. J., Papadopoulou, K. N., and Diliberto, S. (2000). Impact of otter trawling on an eastern Mediterranean commercial trawl fishing ground. ICES J. Mar. Sci. 57, 1340-1351. doi: 10.1006/jmsc.2000.0927

Tiano, J. C., Witbaard, R., Bergman, M. J. N., van Rijswijk, P., Tramper, A., van Oevelen, D., et al. (2019). Acute impacts of bottom trawl gears on benthic metabolism and nutrient cycling. ICES J. Mar. Sci. 76, 1917-1930. doi: 10.1093/ icesjms/fsz060

Trimmer, M., Petersen, J., and Sivyer, D. (2005). Impact of long-term benthic trawl disturbance on sediment sorting and biogeochemistry in the southern North Sea. Mar. Ecol. Prog. Ser. 298, 79-94. doi: 10.3354/meps 298079

Tuck, I. D., Hall, S. J., and Robertson, M. R. (1998). Effects of physical trawling disturbance in a previously unfished sheltered Scottish sea loch. Mar. Ecol. Prog. Ser. 162, 227-242. doi: 10.3354/meps162227

van de Velde, S., Van Lancker, V., Hidalgo-Martinez, S., Berelson, W. M., and Meysman, F. J. R. (2018). Anthropogenic disturbance keeps the coastal seafloor biogeochemistry in a transient state. Sci. Rep. 8:5582.

van Denderen, P. D., Bolam, S. G., Friedland, R., Hiddink, J. G., Noren, K., Rijnsdorp, A. D., et al. (2020). Evaluating impacts of bottom trawling and hypoxia on benthic communities at the local, habitat, and regional scale using a modelling approach. ICES J. Mar. Sci. 77, 278-289. doi: 10.1093/icesjms/fsz219

Wainright, S. C., and Hopkinson, C. S. (1997). Effects of sediment resuspension on organic matter processing in coastal environments: a simulation model. J. Mar. Syst. 11, 353-368. doi: 10.1016/s0924-7963(96)00130-3

Warnken, K. W., Gill, G. A., Dellapenna, T. M., Lehman, R. D., Harper, D. E., and Allison, M. A. (2003). The effects of shrimp trawling on sediment oxygen consumption and the fluxes of trace metals and nutrients from estuarine sediments. Estuarine Coast. Shelf Sci. 57, 25-42. doi: 10.1016/s0272-7714(02) 00316-5

Watling, L., Findlay, R. H., Mayer, L., and Schick, D. F. (2001). Impact of a scallop drag on the sediment chemistry, microbiota, and faunal assemblages of a shallow subtidal marine benthic community. J. Sea Res. 46, 309-324. doi: 10.1016/s1385-1101(01)00083-1

Wenger, A. S., Harvey, E., Wilson, S., Rawson, C., Newman, S. J., Clarke, D., et al. (2017). A critical analysis of the direct effects of dredging on fish. Fish Fisheries 18, 967-985. doi: 10.1111/faf.12218

Zacharia, P. U., Krishnan, A. A., Durgekar, R. N., and Krishnakumar, P. K. (2006). Immediate effects of experimental otter trawling on the physico-chemical parameters of seawater off Mangalore. J. Mar. Biol. Ass. India 48, 200-205.

Conflict of Interest: The authors declare that the research was conducted in the absence of any commercial or financial relationships that could be construed as a potential conflict of interest.

Publisher's Note: All claims expressed in this article are solely those of the authors and do not necessarily represent those of their affiliated organizations, or those of the publisher, the editors and the reviewers. Any product that may be evaluated in this article, or claim that may be made by its manufacturer, is not guaranteed or endorsed by the publisher.

Copyright (C) 2021 Bradshaw, Jakobsson, Brüchert, Bonaglia, Mörth, Muchowski, Stranne and Sköld. This is an open-access article distributed under the terms of the Creative Commons Attribution License (CC BY). The use, distribution or reproduction in other forums is permitted, provided the original author(s) and the copyright owner(s) are credited and that the original publication in this journal is cited, in accordance with accepted academic practice. No use, distribution or reproduction is permitted which does not comply with these terms. 